\title{
POR QUE LOCAIS DEMARCADOS SÃO IMPORTANTES PARA O APARECIMENTO DO EFEITO ATENCIONAL AUTOMÁTICO?
}

Dissertação apresentada ao Programa de Pós-Graduação em Fisiologia Humana do Instituto de Ciências Biomédicas da Universidade de São Paulo, para obtenção do Título de Mestre em Ciências. 


\section{POR QUE LOCAIS DEMARCADOS SÃO IMPORTANTES PARA O APARECIMENTO DO EFEITO ATENCIONAL AUTOMÁTICO?}

Dissertação apresentada ao Programa de Pós-Graduação em Fisiologia Humana do Instituto de Ciências Biomédicas da Universidade de São Paulo, para obtenção do Título de Mestre em Ciências.

Área de concentração: Fisiologia Humana

Orientador: Prof. Dr. Luiz Eduardo Ribeiro do Valle 
DADOS DE CATALOGAÇÃO NA PUBLICAÇÃO (CIP)

Serviço de Biblioteca e Informação Biomédica do

Instituto de Ciências Biomédicas da Universidade de São Paulo

reprodução não autorizada pelo autor

Sais, Fernanda Amadei.

Por que locais demarcados são importantes para o aparecimento do efeito atencional automático? / Fernanda Amadei Sais. -- São Paulo, 2011.

Orientador: Luiz Eduardo Ribeiro do Valle.

Dissertação (Mestrado) - Universidade de São Paulo. Instituto de Ciências Biomédicas. Departamento de Fisiologia e Biofísica. Área de concentração: Fisiologia Humana. Linha de pesquisa: Processos sensoriais e motores.

Versão do título para o inglês: Why are placeholders important to the manifestation of the automatic attentional effect?.

Descritores: 1. Atenção seletiva 2 . Atenção visual 3 . Psicofísica 4. Neurociências 5. Tempo de reação 6. Captura atencional I. Valle, Luiz Eduardo Ribeiro do II. Universidade de São Paulo. Instituto de Ciências Biomédicas. Programa de Pós-Graduação em Fisiologia e Biofísica III. Título. 
Candidato(a):

Título da Dissertação:

Orientador(a):
Fernanda Amadei Sais.

Por que locais demarcados são importantes para o aparecimento do efeito atencional automático? .

A Comissão Julgadora dos trabalhos de Defesa da Dissertação de Mestrado, em sessão pública realizada a .............. ..........
( ) Aprovado(a)
( ) Reprovado(a)

Examinador(a): Assinatura:

Nome:

Instituição:

Examinador(a): Assinatura:

Nome:

Instituição:

Presidente:

Assinatura:

Nome:

Instituição: 
São Paulo, 25 de maio de 2009.

\section{PARECER 894/CEP}

Prezada Senhora,

Atendendo sua solicitação, a Comissão de Ética em Pesquisas com Seres Humanos do ICB, em sua $95^{\mathrm{a}}$ reunião realizada em 22.05.09, analisou o projeto de sua responsabilidade intitulado: "Por que locais demarcados são importantes para o aparecimento do efeito atencional automático?".

Informo a V.Sa. que, após análise e discussão, o referido projeto foi aprovado por esta Comissão.

Lembramos que cabe ao pesquisador elaborar e apresentar a este Comitê, relatórios anuais (parciais ou final), de acordo com a resolução 196/06 do Conselho Nacional da Saúde, item IX.2 letra c.

O primeiro relatório deverá ser encaminhado à Secretaria deste CEP em 22 de maio de 2010.

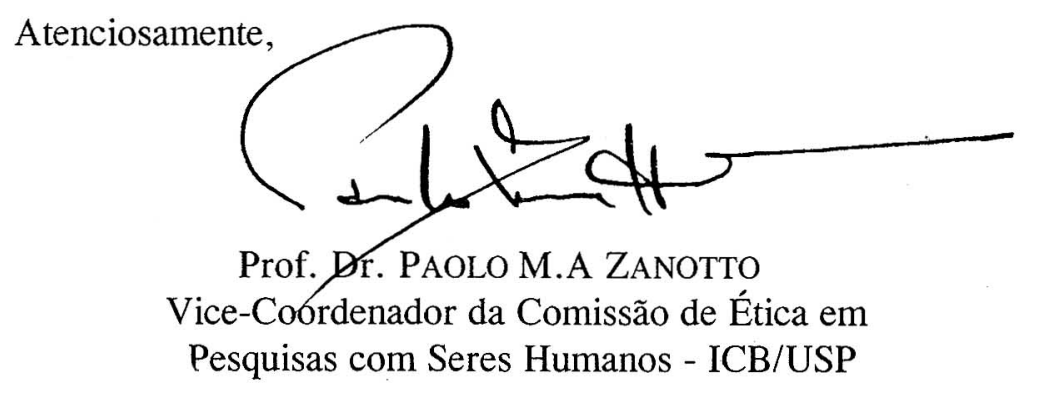

Ilma Sra.

FERNANDA AMADEI SAIS

Departamento de Fisiologia e Biofísica

Instituto de Ciências Biomédicas -USP 
In memoriam

Miriam Amadei Sais 


\section{AGRADECIMENTOS}

Ao meu pai, pelo apoio.

À minha irmã, por me inspirar.

Aos meus amigos do laboratório, por sempre ouvirem minhas dúvidas práticas e existenciais com paciência e atenção.

Aos professores Gilberto, Marcus Vinicius e André Frazão pelas observações feitas no Exame de Qualificação.

A todos os estudantes que participaram como voluntários nos experimentos, sem os quais esse trabalho não teria sido possível.

Ao Professor Ribeiro, por tudo, mas sobretudo pelas longas discussões que me motivam desde o primeiro dia em que entrei em seu laboratório.

À FAPESP, pelo apoio financeiro. 
"As teorias são redes, lançadas para capturar aquilo que denominamos 'o mundo': para racionalizá-lo, explicá-lo, dominálo. Nossos esforços são no sentido de tornar as malhas da rede cada vez mais estreitas." Karl Popper 


\section{RESUMO}

SAIS, F. A. Por que locais demarcados são importantes para o aparecimento do efeito atencional automático? 2011. 78 f. Dissertação (Mestrado em Fisiologia Humana) - Instituto de Ciências Biomédicas, Universidade de São Paulo, São Paulo, 2011.

Existem muitos trabalhos na literatura mostrando que um estímulo periférico não informativo espacialmente captura a atenção para o local de seu aparecimento. Por outro lado, existem uma série de outros trabalhos em que não são observados efeitos comportamentais nem eletrofisiológicos da captura atencional nessas condições. Tem sido bastante discutida a idéia de que a captura da atenção por um estímulo estaria sujeita a uma modulação e dependeria da tarefa realizada. Assim, um estímulo só capturaria a atenção se tivesse alguma relação com outro estímulo de interesse para o sujeito como, por exemplo, se tivesse a mesma cor do estímulo alvo. Nós investigamos, no Experimento 1A e 1B, em uma tarefa de escolha de local, uma situação em que aparece o efeito atencional quando existem demarcações nos locais de aparecimento dos estímulos, mas, se não existem essas demarcações, o efeito atencional simplesmente desaparece. A única diferença entre os procedimentos era a presença ou ausência de demarcações, todos os demais parâmetros eram idênticos. Nesse experimento, investigamos se, na condição sem demarcações, o estímulo não capturaria a atenção por ser filtrado em estágios precoces de processamento. Se isso fosse verdade, não seria esperado que o estímlo fosse capaz de gerar outro tipo de efeito sobre o comportamento. Por isso, testamos se, apesar de não capturar a atenção, o estímulo provocaria um outro efeito frequentemente associado à captura atencional, a inibição de retorno. Observamos que o estímulo precedente provocou a inibição de retorno e, portanto, a razão pela qual o estímulo precedente não captura a atenção nessas condições não deve ser atribuída a uma filtragem precoce no seu processamento. Além disso, investigamos, nos experimentos 2, 3 e 4, se alterações no fundo da tela, que gerasse maior competição no processamento dos estímulos presentes na cena visual, poderiam levar à captura da atenção, mesmo sem a presença das demarcações classicamente utilizadas. De fato, observamos que quando a intensidade dos estímulos competidores presentes na tela era alta, o estímulo precedente passou a capturar a atenção. Explicamos esse resultado com a hipótese de que as demarcações são importantes por adicionarem ruído ao processamento dos estímulos apresentados, influenciando a representação desses estímulos e, portanto, a possibilidade de um estímulo capturar a atenção. Por fim, no experimento 5A e 5B, investigamos se os resultados da tarefa de escolha de local seriam repetidos em uma tarefa de discriminação de forma. Observamos que os resultados 
foram semelhantes, embora o efeito da captura atencional pelo estímulo precedente não tenha sido tão evidente. Esse resultado está de acordo com trabalhos da literatura em que o efeito atencional é menor em tarefas de discriminação de forma do que em tarefas de detecção, possivelmente pela necessidade de direcionar a atenção para processamentos internos envolvidos na identificação dos estímulos.

Palavras-chave: Neurociências. Psicofísica. Tempo de reação. Atenção Seletiva. Atenção Visual. 


\begin{abstract}
SAIS, F. A. Why are placeholders important to the manifestation of the automatic attentional effect? 2011. 78 p. Master thesis (Human Physiology) - Instituto de Ciências Biomédicas, Universidade de São Paulo, São Paulo, 2011.
\end{abstract}

A number of studies show that an uninformative peripheral stimulus captures attention to the location in space where it appears. On the other hand, there are plenty of other studies in which neither behavioural nor eletrophysiological evidences of attentional capture are observed in such conditions. The idea that attentional capture is modulated and depends on the task at hand has been acutely argued in the literature. Thus, a stimulus would capture attention only if it has some resemblance with another stimulus of interest to the subjetc, such as if both shared the same color. In Experiment $1 \mathrm{~A}$ and $1 \mathrm{~B}$ we investigated, using a local choice task, a situation in which if placeholders are presented on the screen the attentional effect is shown but, if the placeholders are absent, the attentional effect desappears. The only difference between the two procedures was the presence or absence of the placeholders, all other parameters remained constant. In this experiment we investigated if the peripheral stimulus did not capture attention in the absence of the placeholders because it was filtered in early stages of processing. If that were the case, we would not expect the stimulus to generate any other effect on behaviour. Therefore, we tested if although the stimulus did not capture attention in the absence of placeholders it would still generate another effect often associated with attentional capture, the inhibition of return. We did observe the inhibition of return at this experiment, hence it follows that the reason why the stimulus did not capture attention can not me atribuited to a filtering in early stages of processing. Besides that, we investigated in experiments 1, 2 and 3 if changes on screen background generating an ehnancement of competition between the processing of stimuli present on the visual scene would produce attentional capture even in the absence of the placeholders. Indeed, we observed that when the competing stimulus intensity were high the peripheral stimuli was able to capture attention. We explain this result with the hipothesis that the placeholders are important because they add noise to the stimuli processing and affect the stimuli representation, acting on the ability of a stimulus to capture attention. Lastly, in experiment $5 \mathrm{~A}$ and $5 \mathrm{~B}$ we investigated if the results observed in the location choice task would be replicated in a form discrimination task. We found similar results, even though the attentional capture were not as unequivocal in the discrimination task as it were in the location choice task. This result is in accordance with 
other studies in the literature that show a smaller attentional effect in discrimination tasks than in detection tasks, feasibly because of the need to direct attentional resources to internal processing related to the stimuli identification.

Key-words: Neuroscience. Psychophysics. Reaction Time. Selective Attention. Visual Attention. 


\section{LISTA DE FIGURAS}

Figura 1: Representação da sequência de apresentação dos estímulos e suas durações ....... 28

Figura 2: Tempos de reação observados no Experimento 1 .......................................30

Figura 3: Tempos de reação observados no Experimento 2 .............................36

Figura 4: Tempos de reação observados no Experimento 3 ................................40

Figura 5: Tempos de reação observados no Experimento 4 ...............................43

Figura 6: Tempos de reação observados no Experimento 5 .................................48 


\section{SUMÁRIO}

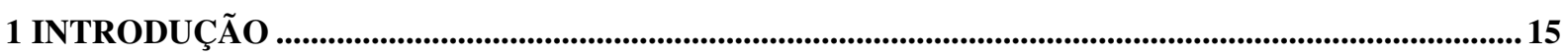

2 OBJETIVOS .................................................................................................................................. 24

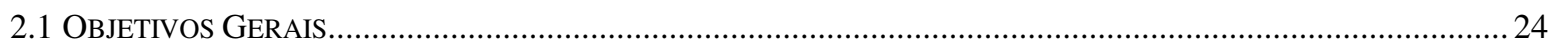

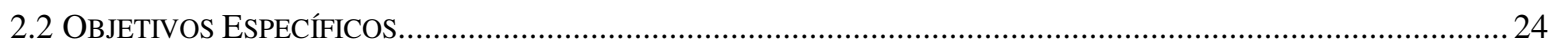

3 EXPERIMENTO 1................................................................................................................................25

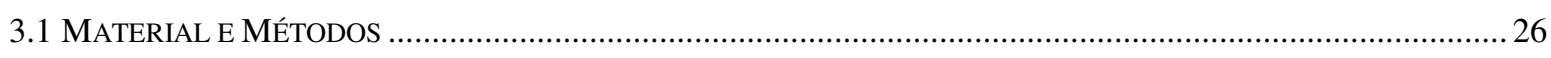

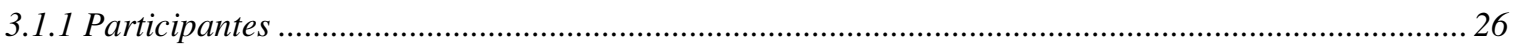

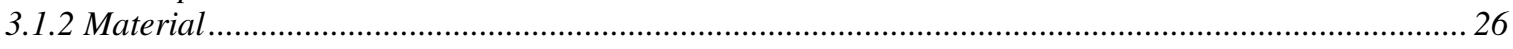

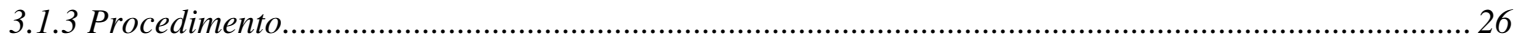

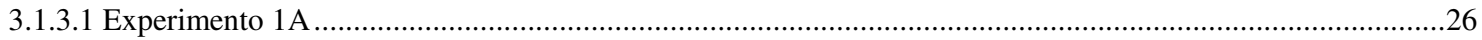

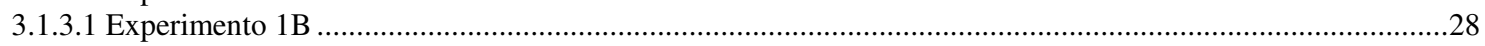

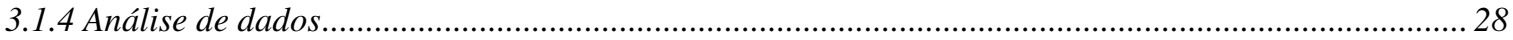

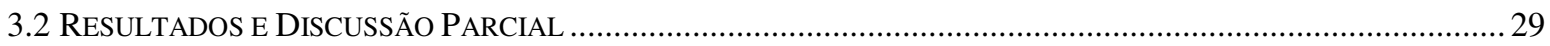

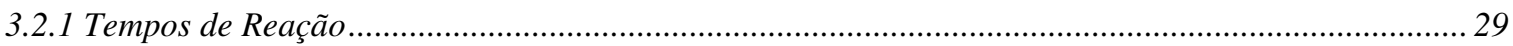

3.2.2 Discussão Parcial...................................................................................................................... 31

4 EXPERIMENTO 2....................................................................................................................................................34

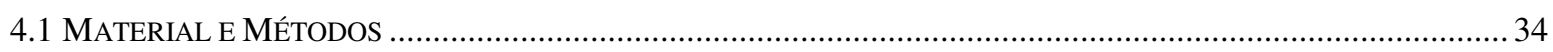

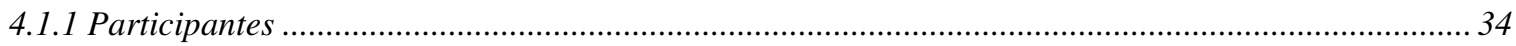

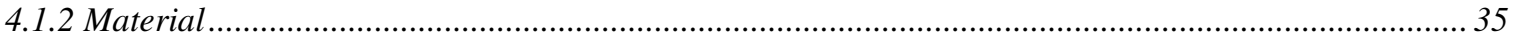

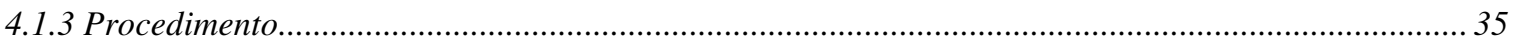

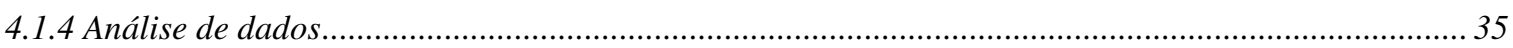

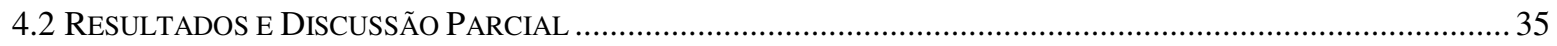

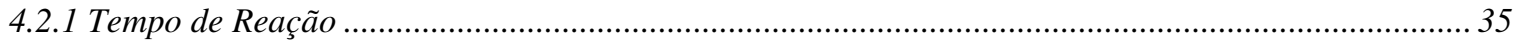

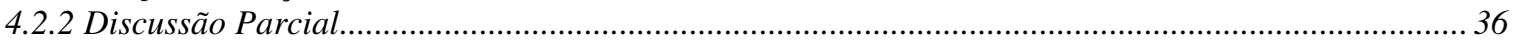

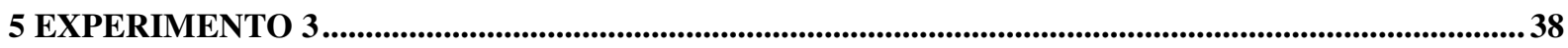

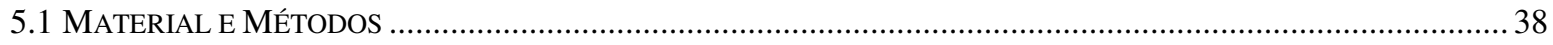

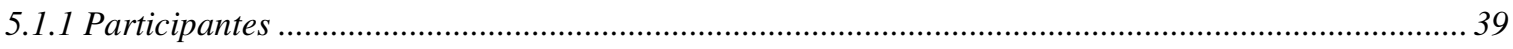

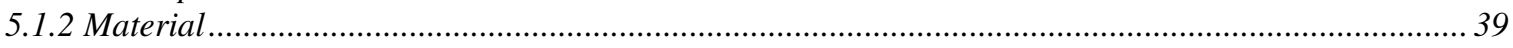

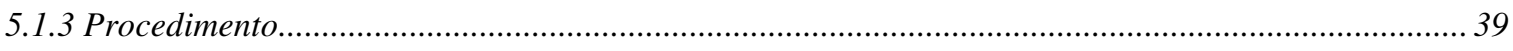

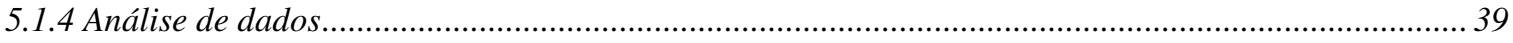

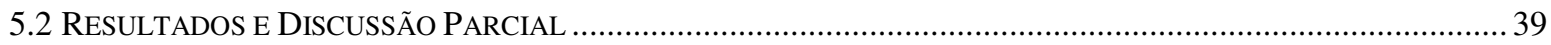

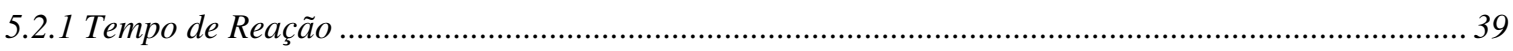

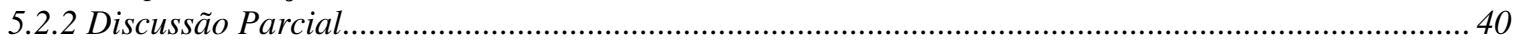

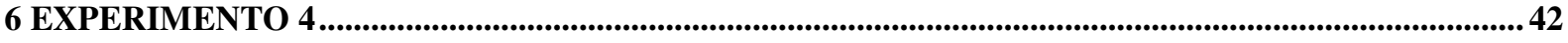

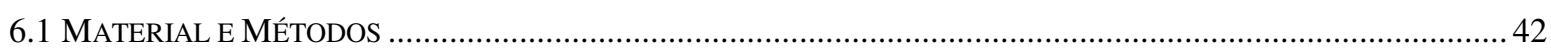

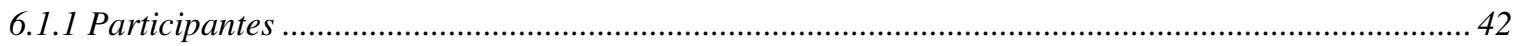

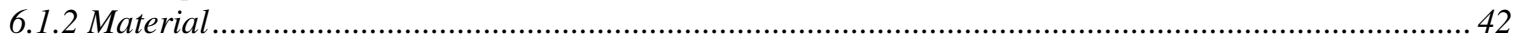

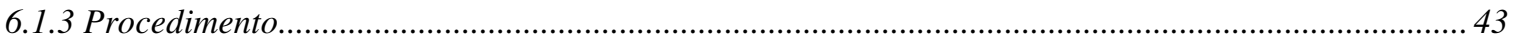

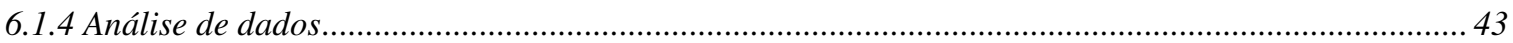

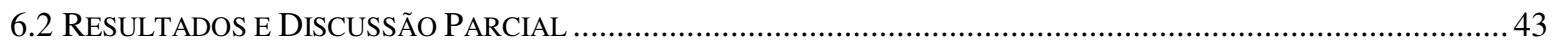

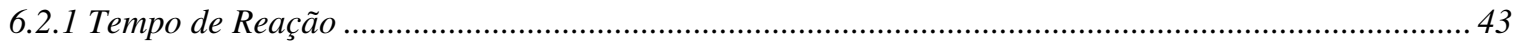

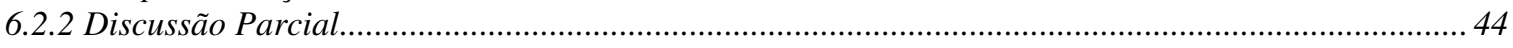

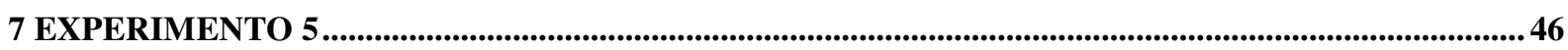

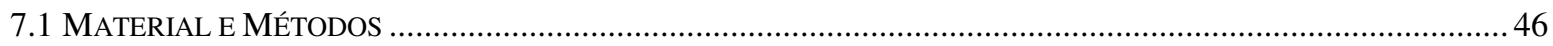

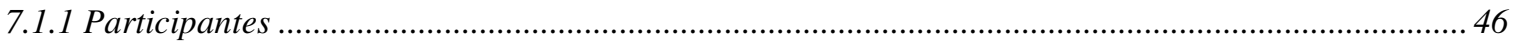

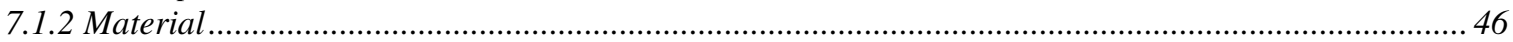

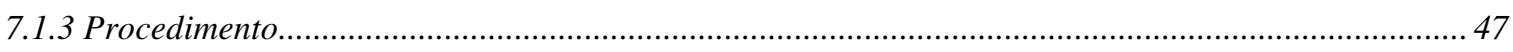

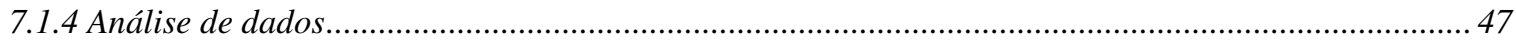




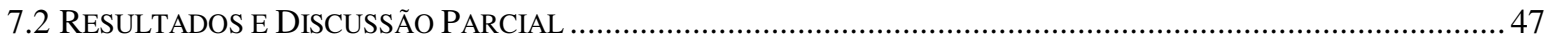

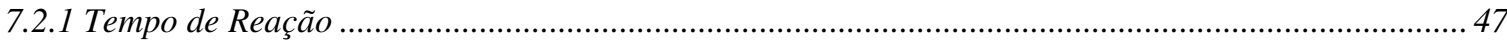

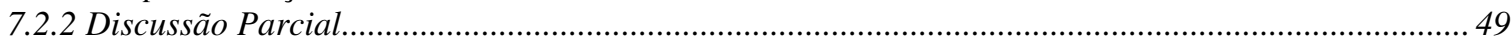

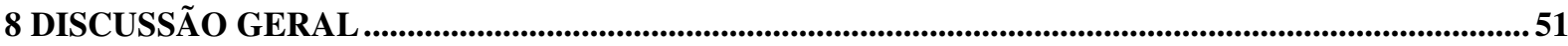

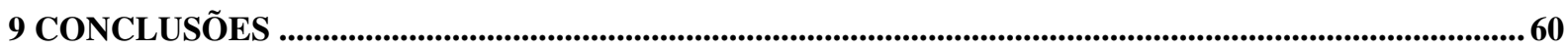

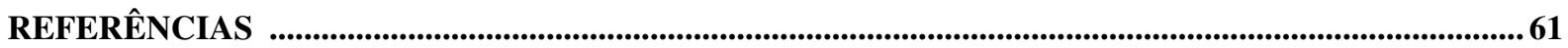

ANEXO A - TERMO DE ANUÊNCIA ................................................................................................68

ANEXO B - QUESTIONÁRIO DE EDINBURGH (ADAPTADO) ..............................................................69

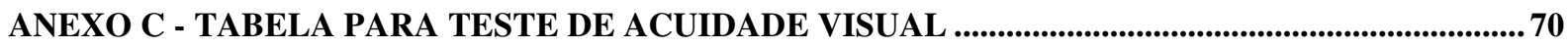

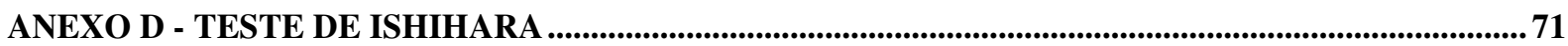

ANEXO E - TABELAS DE DADOS DO EXPERIMENTO 1 ................................................................72

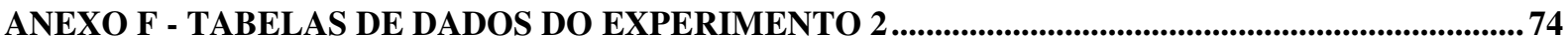

ANEXO G - TABELAS DE DADOS DO EXPERIMENTO 3 ............................................................... 75

ANEXO H - TABELAS DE DADOS DO EXPERIMENTO 4 .........................................................................76

ANEXO I - TABELAS DE DADOS DO EXPERIMENTO 5............................................................................. 77 


\section{INTRODUÇÃO}

Embora em nossa experiência diária sejamos capazes de jurar que temos acesso a todas as informações visuais apresentadas diante de nossos olhos, uma afirmação desse tipo não resiste a uma análise comportamental e fisiológica do funcionamento do nosso sistema visual. Existem processos de seleção de informação atuando em todas as fases de processamento sensorial, desde o nível dos receptores até processamentos que levam à realização de uma ação motora ou a processos cognitivos tais como atenção, memória e consciência. A seleção feita já pelos receptores na retina modula a entrada de informações no sistema visual: os receptores são distribuídos de modo que não há uma ótima resolução de processamento em todas as regiões: uma alta concentração de receptores na fóvea garante alta resolução no processamento de estímulos centrais, mas perifericamente a concentração de receptores é menor e a resolução também, com perda massiva de acuidade a apenas alguns graus da fóvea.

Apesar dessas reduções na entrada de informação no sistema, a quantidade de informações que passa ainda é muito grande. Assim, existem mecanismos antencionais que selecionam apenas uma parcela dos estímulos que receberá um processamento mais extensivo, enquanto o restante dos estímulos passará por uma análise bem mais limitada. Esse é um dos motivos da enorme dificuldade de encontrar as chaves antes de sair de casa quando não as deixamos sempre no mesmo lugar, ou de descobrir o segredo de um truque de mágica bem apresentado. Se estivéssemos o tempo todo processando todas as informações presentes em uma cena com a mesma eficiência, certamente sairíamos de casa bem mais rápido e o mágico teria mais dificuldades, por sua vez, em garantir seu ganha pão.

Desde a antiguidade já se notava que a percepção sensorial não é um fenômeno puramente passivo: Aristóteles não menciona explicitamente a atenção, mas questiona a possibilidade de que alguém seja capaz de perceber dois objetos simultaneamente, argumentando que "de dois movimentos o mais forte sempre tende a deslocar o mais fraco". Embora no século XVII os principais aspectos da fenomenologia da atenção já tivessem sido registrados e as principais posições teóricas já tivessem sido formuladas no final do século XVIII, foi nos anos de 1930 que a atenção foi introduzida na disciplina da psicologia como um tópico de destaque, com as discussões de Wolf. Wolf formulou algumas generalizações sobre a atenção. Uma delas, por exemplo, descreve uma relação inversa entre a intensidade da 
atenção e a quantidade de informação abarcada por ela: quanto maior a atenção, menor a parcela do campo visual atendida. Essas generalizações são formuladas como proporções, mas não são acompanhadas de dados quantitativos que suportem as relações (HATFIELD, 1998).

A introdução de dados experimentais nos estudos sobre a atenção ocorreu a partir dos trabalhos de Hermann von Helmholtz, na segunda metade do século XIX. Helmholtz estava particularmente interessado em como nós somos capazes de direcionar a atenção para uma região do campo visual diferente daquela para a qual nossos olhos estão apontando. Para estudar esse fenômeno ele construiu uma espécie de taquitoscópio, por meio do qual conseguia apresentar estímulos visuais por intervalos muito curtos de tempo. Ele matinha sempre o olhar fixo no centro do campo visual. Antes de apresentar um cartão com letras impressas, ele escolhia uma região do espaço para a qual concentrar a sua atenção. Surpreendentemente, durante o pequeno intervalo de iluminação, as letras que estavam na área em que a atenção havia sido concentrada eram mais identificáveis e as letras que estavam localizadas nas vizinhanças do ponto de fixação ocular eram mais difíceis de ser identificadas. Essa foi a primeira técnica utilizada para estudar a capacidade de orientar a atenção independentemente da focalização ocular, e evidencia o papel determinante da atenção para uma identificação eficiente dos objetos (WRIGHT; WARD, 2008).

Diferentemente do que ocorre na auto-experimentação de Helmholtz, um estímulo pode capturar a atenção em situações em que o sujeito não expressa vontade prévia na mobilização atencional, não é dada nenhuma instrução nesse sentido e a orientação da atenção para esses estímulos não oferece nenhuma vantagem evidente (passível de ser declarada pelo sujeito) para a realização de uma tarefa em andamento que pudesse levar o sujeito a prestar atenção voluntariamente a esses estímulos. Classicamente, pode-se observar esse tipo de captura atencional de duas maneiras: pela busca de um objeto alvo em meio a outros estímulos competidores, que pode ser estudada tarefas de busca visual; ou pela resposta a um objeto alvo quando este ocorre em um local para o qual a atenção tenha sido previamente alocada, que pode ser estudada em tarefas que apresentam um estímulo periférico que precede o alvo em alguns milissegundos (BRIAND; KLEIN, 1987). Por esses dois procedimentos é possível estudar a mobilização involuntária da atenção, amplamente considerada um processo de natureza automática. Em tarefas de busca visual, são estímulos que não tem nenhuma relação com o estímulo alvo que interessa ao sujeito e, no entanto, mesmo assim provocam um atraso no tempo de resposta quando estão presentes na tela. No caso de tarefas de localização espacial com estímulos precedentes, os estímulos precedentes não predizem de 
nenhuma maneira o local de aparecimento do estímulo alvo, tendo igual probabilidade de ocorrer no mesmo local em que posteriormente aparecerá o estímulo alvo ou de ocorrer em qualquer outro local.

É atribuído a Posner e seus colaboradores o desenvolvimento e refinamento desse procedimento de orientação encoberta da atenção que utiliza estímulos precedentes (POSNER, 1980; POSNER; COHEN, 1984). Nosso trabalho utiliza tarefas de localização espacial, adaptadas a partir de um procedimento experimental de Posner. Nesse procedimento, cada tentativa (apresentação do estímulo alvo a que o sujeito deve responder) se inicia com o aparecimento de um ponto de fixação no centro da tela e de dois quadrados, um à direita e outro à esquerda desse ponto central, demarcando os locais em que serão apresentados os estímulos. O sujeito é instruído a manter o olhar fixo no centro durante todo o procedimento e a responder ao estímulo alvo que aparecerá uma parte das vezes dentro do quadrado da direita e uma parte das vezes dentro do quadrado da esquerda. Alguns milissegundos antes do aparecimento do estímulo alvo é apresentado o estímulo precedente, que consiste numa alteração de luminância em um dos quadrados. Esse estímulo precedente tem a mesma probabilidade de ocorrer no mesmo local em que posteriormente é apresentado o alvo e no local oposto ao que posteriormente é apresentado o alvo. Em intervalos curtos entre o estímulo precedente e o estímulo alvo (até aproximadamente 300 milissegundos) costuma-se observar que os tempos de resposta ao alvo são significativamente mais baixos quando o alvo é apresentado no mesmo local em que foi apresentado o estímulo precedente e significativamente mais altos quando o alvo é apresentado no local oposto ao da apresentação do estímulo precedente. Essa diferença nos tempos de resposta é atribuída à mobilização da atenção pelo estímulo precedente para a região do espaço em que ele foi apresentado.

Até a década de 1990 praticamente não se encontra na literatura questionamentos acerca da capacidade de um estímulo capturar a atenção automaticamente nessas condições. No entanto, principalmente a partir de resultados obtidos por Folk et al. (1992), esse mecanismo passou a ser questionado, com o uso de variações dessa tarefa em que não eram observadas respostas mais rápidas no mesmo local de apresentação de um estímulo precedente quando o estímulo precedente não possuía alguma característica física compartilhada com o estímulo alvo. Esses resultados deram origem à hipótese da captura contingente da atenção, segundo a qual a atenção é orientada involuntariamente por um estímulo apenas quando esse estímulo possui um atributo que é crítico para a performance do sujeito na realização da tarefa. 
Cabe aqui notar que os resultados comportamentais obtidos em procedimentos experimentais que visam a observar os efeitos da atenção podem ser atribuídos ao mecanismo de captura atencional ou à natureza dos efeitos provocados pela alocação atencional. Assim, quando observamos um resultado negativo como a ausência de efeito atencional, a princípio podemos interpretar esse resultado de dois modos: podemos supor que a atenção não foi capturada ou podemos supor que a atenção foi capturada, mas seu efeito não foi observado.

Supondo que a ausência de um efeito observável da atenção signifique que a atenção não foi capturada, ou seja, que não teriam sido ativados os mecanismos que levam a um processamento seletivo dos estímulos em níveis perceptivos e motores, a determinação das condições em que se observa o efeito atencional e das condições em que não se observa esse efeito permite a identificação de quais são os fatores críticos envolvidos na ativação desse tipo de processamento que caracteriza a captura atencional. A partir da identificação desses fatores podem ser elaborados modelos teóricos do processamento neural que corresponde à fenomenologia da atenção, o que torna evidente o interesse de situações experimentais em que o efeito atencional observado por Posner não é verificado em variações do seu procedimento experimental.

Resultados desse tipo têm se multiplicado nas últimas duas décadas, e estudos mais recentes de eletrofisiologia mostram que não ocorre atividade elétrica associada à atenção nas condições em que não se observam efeitos comportamentais da captura atencional (LEBLANC; PRIME; JOLICOEUR, 2008; EIMER; KISS, 2008, 2010; KISS et al., 2008). Nesses estudos, a presença do componente N2pc fornece um marcador temporal preciso da orientação da atenção no espaço. O componente N2pc é caracterizado como uma deflexão negativa registrada por eletrodos posicionados no escalpo posterior, contralaterais ao lado de um estímulo atendido, tipicamente entre 180 ms e 300 ms após o aparecimento do estímulo.

Em nosso laboratório também temos um conjunto de experimentos em que diferenças na apresentação dos estímulos resultam na ausência de efeitos facilitadores sobre a resposta. Macea et al. (2006) mostram que a atenção não é mobilizada quando o estímulo alvo é facilmente discriminável, e que a atenção é mobilizada quando a discriminação necessária para identificar o alvo é mais difícil.

A explicação mais clássica para a orientação involuntária da atenção considera que a captura atencional ocorre de maneira puramente automática, direcionada pelos atributos físicos dos estímulos presentes em uma cena visual. De fato, diversos atributos presentes em uma cena visual são processados paralelamente, tais como cor, orientação espacial, 
intensidade luminosa, etc. Alguns desses atributos se destacam em relação aos demais, ou seja, são mais salientes. Picos nesse mapa de saliência seriam capazes de direcionar a mobilização da atenção por gerarem alças de feedback que intensificariam a atividade das redes neurais relacionadas ao estímulo saliente (THEEUWES, 2010). Desse modo, a atenção seria um mecanismo que intrinsecamente estaria aumentando o processamento do estímulo de interesse, ou seja, do sinal, se pensarmos na cena visual em termos de sinal e ruído e que o sinal corresponde ao processamento do estímulo de interesse e o ruído corresponde a quaisquer outros processamentos não relacionados diretamente ao estímulo de interesse. Notese que, por esse mecanismo, qualquer estímulo que se destaque no mapa de saliência direcionará a atenção para si e levará a uma subsequente amplificação do sinal correspondente ao seu processamento. Esse mecanismo não explica adequadamente, sem a elaboração de hipóteses adicionais, os resultados em que a captura da atenção por um estímulo precedente é contingente e ocorre apenas quando este é semelhante ao estímulo alvo.

Por outro lado, a explicação da captura contingente da atenção, nos termos propostos por Folk e Remington (1992), não dá conta de explicar os resultados em que a discriminabilidade do estímulo alvo determina se a atenção será mobilizada ou não. Nessa situação, foi mostrado que o estímulo precedente não é sempre capaz de mobilizar a atenção, mas que a semelhança física entre o estímulo precedente e o estímulo alvo não é determinante. Assim, parece ser necessária uma hipótese mais abrangente para explicar o mecanismo da captura involuntária da atenção, que possa explicar um maior número de tarefas em que essa captura não ocorre.

O procedimento original de Posner e suas variações utilizam demarcações nos locais de aparecimento dos estímulos na tela. No entanto, Woodman, Arita e Luck (2009) realizaram um experimento em que a atenção era orientada voluntariamente para um local da tela utilizando uma pista visual com $100 \%$ de validade e observaram que o componente N2pc precedia o aparecimento do alvo apenas quando havia demarcações presentes na tela durante todo o teste. Na ausência das demarcações, esse componente, associado à mobilização atencional, foi observado apenas após o aparecimento do alvo na tela. A explicação dos autores para este resultado é que o mecanismo atencional associado ao componente N2pc seleciona objetos e não apenas a localização no espaço. As demarcações seriam objetos atuando como âncoras para a focalização da atenção, segundo esse ponto de vista.

Resultados anteriores do nosso laboratório (GRECHI, 2006) sugerem que as demarcações são importantes também para a mobilização automática da atenção por estímulos 
precedentes periféricos. Utilizando uma tarefa de localização espacial, Grechi (2006) observou que o efeito atencional, presente quando eram utilizadas demarcações na tela, desaparecia em uma tarefa idêntica em que as demarcações não estavam presentes.

Esse resultado é difícil de ser explicado pela teoria de que qualquer estímulo saliente é capaz de mobilizar a atenção para o local de seu aparecimento, uma vez que o estímulo precedente utilizado é exatamente o mesmo nos experimentos com e sem demarcações. Se de fato a mobilização atencional é direcionada pela saliência do estímulo e um estímulo saliente sempre captura atenção, conforme argumenta Theeuwes (2010), duas hipóteses poderiam explicar a ausência de efeito quando não há demarcações na tela.

A primeira hipótese é que ocorreria um mascaramento anterógrado do estímulo precedente sobre o estímulo alvo, uma vez que o estímulo precedente, aparecendo na tela sem as demarcações, representa uma maior alteração de luminância do que quando ele aparece sobreposto às demarcações (GRECHI, 2006; KEYSERS; PERRET, 2002). Nesse caso, o estímulo precedente ativaria mecanismos atencionais, mas, devido à inibição sensorial do processamento do estímulo alvo, o efeito da captura atencional não seria observado no comportamento.

A segunda hipótese é que a atenção seria capturada pelo estímulo precedente e rapidamente desengajada, de modo que quando o estímulo alvo aparecesse ela não estaria mais facilitando o processamento daquele local. Esse argumento é utilizado por Theeuwes e Godijn (2002) para explicar a ausência de efeito atencional quando o estímulo precedente é irrelevante para a tarefa. Segundo os autores, nessas condições é possível observar uma inibição de retorno, caracterizada pela inibição da resposta em um local previamente atendido e que é utilizada como evidência de que a atenção esteve previamente orientada para o local em que ela ocorre. Folk e Remington (2006), no entanto, mostram evidências contrárias à hipótese do rápido desengajamento da atenção, utilizando medidas de efeito de compatibilidade e também de inibição de retorno como indicadores da captura atencional.

É igualmente difícil explicar que um estímulo precedente não capture a atenção na ausência de demarcações utilizando a idéia da captura contingente da atenção uma vez que, novamente, o estímulo precedente e o estímulo alvo utilizado na presença ou na ausência de demarcações são os mesmos, a semelhança entre o estímulo precedente e o estímulo alvo é a mesma nas duas situações. 
A explicação utilizada por Woodman, Arita e Luck (2009) de que o mecanismo atencional seleciona objetos e não apenas a localização no espaço poderia, a princípio, fornecer uma explicação para esses resultados, caso se aplicasse também à captura automática: se o mecanismo atencional de fato seleciona objetos e não apenas locais no espaço, é possível que em um experimento de localização espacial com estímulos precedentes não houvesse tempo para a focalização da atenção após o aparecimento do estímulo precedente, uma vez que o estímulo precedente não fica presente na tela durante toda a tentativa e as assincronias entre o estímulo precedente e o estímulo alvo utilizadas nesses experimentos são curtas. No entanto, essa explicação não dá conta dos resultados em que se evidencia a captura contingente da atenção (FOLK et al., 1992), tampouco dos resultados de Macea et al (2006).

Pode-se adotar uma explicação que considera tanto o modelo de captura contingente da atenção, como o modelo de captura da atenção direcionada por um mapa de saliência. Nesse caso, outros fatores contextuais podem tornar o estímulo precedente relevante para a realização da tarefa. A determinação das configurações atencionais adotadas em uma tarefa e que estariam modulando o processamento dos estímulos não dependeria apenas de processamentos hierarquicamente superiores, ou seja, não seria apenas "de cima para baixo". Pelo contrário, combinaria os processamentos ocorrendo "de baixo para cima", que refletiriam a saliência dos estímulos, e processamentos "de cima para baixo", criando um mapa de prioridade. Em última análise, a mobilização da atenção refletiria uma atividade caracterizada pelo balanço dessas duas influências (FECTEAU; MUNOZ, 2006; LAMY; EGETH, 2004; FOLK; REMINGTON, 1998). É possível explicar desse modo tanto os resultados de Theeuwes (2010), como os de Folk et al. (1992) e os de Macea et al. (2006): quando um estímulo é muito saliente, a influência do mapa de saliência sobre o mapa de prioridade pode ser preponderante. No entanto, se houver uma sintonização forte do sistema para um dado atributo, determinada pela relevância desse atributo para a tarefa, essas configurações é que terão maior influência sobre o mapa de prioridade. Do mesmo modo, quando o estímulo alvo é muito discriminável dos demais, o sistema se sintonizaria muito fortemente para os atributos que caracterizam o estímulo de interesse e o processamento do estímulo precedente, com atributos irrelevantes para a tarefa, seria inibido.

Adotando esse modelo, como explicar que o estímulo precedente capture a atenção quando se utilizam as demarcações, mas não capture a atenção quando não se utilizam as demarcações? Nossa hipótese é que as demarcações tornem os estímulos precedente e alvo 
menos salientes, de modo que sejam menos discrimináveis um do outro. Nessa situação, o estímulo precedente, sendo menos distinto, seria considerado relevante pelo sistema e mobilizaria a atenção para o local de seu aparecimento. Na ausência de demarcações, não existem estímulos competidores e tanto o estímulo precedente como o estímulo alvo são mais facilmente discrimináveis. Nessa situação, o estímulo precedente não mobilizaria a atenção por ser considerado irrelevante pelo sistema.

Assim, utilizamos em quatro experimentos tarefas de localização espacial adaptadas do procedimento experimental de Posner e Cohen (1984) para verificar se a atenção é mobilizada de maneira diferente por um estímulo periférico não informativo espacialmente na presença ou na ausência de demarcações, se a mobilização da atenção é de fato modulada e se essa modulação depende da discriminabilidade dos estímulos.

O primeiro experimento teve o objetivo de repetir os dados em que a atenção não é mobilizada na ausência de demarcações e, adicionalmente, verificar se o estímulo precedente gera uma inibição de retorno nessas condições. Foram utilizadas, portanto, as assincronias de 100, 400 e 800 milissegundos entre o início dos estímulos precedente e alvo. Ele foi dividido em um experimento A, em que foi utilizado o procedimento com posições demarcadas que serve como controle, e um experimento B, em que não foram apresentadas demarcações na tela.

O segundo experimento utilizou o mesmo procedimento do experimento $\mathrm{B}$, sem demarcações, mas com assincronias de 50, 100, 150, 200 e 250 milissegundos entre o início do estímulo precedente e o início do estímulo alvo, com a intenção de testar as hipóteses de mascaramento anterógrado e de desengajamento da atenção.

O terceiro experimento utilizou o mesmo procedimento do segundo experimento, mas dessa vez foram apresentadas durante toda a tentativa linhas verticais e horizontais na tela, formando um fundo quadriculado. Pretendíamos, assim, adicionar ruído sensorial ao processamento dos estímulos, tornando o estímulo precedente e o estímulo alvo menos salientes e, portanto, menos discrimináveis. Esperávamos que, se a explicação a partir de um mapa de prioridade estivesse correta, o estímulo precedente seria capaz de mobilizar a atenção nesse experimento, a despeito da ausência das demarcações na tela.

Uma vez que os resultados do segundo experimento não seriam totalmente conclusivos em relação a hipóteses alternativas para explicar o possível aparecimento de um efeito atencional no terceiro experimento, realizamos um quarto experimento, idêntico ao 
experimento anterior, exceto pelo fato de que as linhas verticais e horizontais que formavam o padrão quadriculado tinham uma intensidade menor nesse experimento, de modo que não constituíam um ruído significativo capaz de tornar os estímulo menos discrimináveis. Esperávamos que, nesse caso, o estímulo precedente não fosse capaz de mobilizar a atenção. 


\section{OBJETIVOS}

\subsection{Objetivos Gerais}

Nosso objetivo é examinar fatores associados à importância da utilização de demarcações no local de aparecimento do estímulo alvo para a captura atencional e, a partir desses fatores, compreender melhor os mecanismos envolvidos na captura atencional por um estímulo precedente.

\subsection{Objetivos Específicos}

Pretendemos:

1) Comparar os efeitos observados quando se utilizam os mesmos estímulos precedente e alvo com a utilização de demarcações e sem a utilização das demarcações, tanto nas assincronias curtas em que, de acordo com a literatura tradicional se espera uma facilitação da resposta, como nas assincronias mais longas em que se espera uma inibição de retorno (Experimento 1A e 1B);

2) Testar a hipótese de que a discriminabilidade do estímulo alvo é um fator crítico associado à presença de demarcações, que pode modular a captura atencional (Experimentos 2, 3 e 4).

3) Verificar se em uma tarefa de discriminação de forma a discriminabilidade do estímulo alvo provoca os mesmos efeitos sobre a modulação da captura atencional observados em uma tarefa de escolha de local (Experimento 5A e 5B). 


\section{EXPERIMENTO 1}

Uma vez que os achados de Grechi (2006) indicavam que a utilização de demarcações nos locais de aparecimento dos estímulos era importante para a mobilização automática da atenção por um estímulo precedente, e Woodman et al. (2009) observaram diferenças interessantes na atividade elétrica associada à atenção dependendo da utilização ou não de demarcações, esse primeiro experimento tem por objetivo uma comparação mais detalhada da capacidade de um estímulo precedente mobilizar a atenção quando existem posições demarcadas na tela e quando essas demarcações não estão presentes.

Com esse intuito, consideramos também o efeito inibitório mais tardio normalmente relatado em procedimentos derivados dos experimentos de Posner, designado por inibição de retorno. Este processo causa uma lentificação do tempo de reação ao estímulo alvo no local de aparecimento do estímulo precedente.

A natureza desse processo inibitório e sua relação com a atenção ainda são questões debatidas na literatura (POSNER et al., 1985; KLEIN, 2000; THEEUWES; GODJIN, 2002; FOLK; REMINGTON, 2006; BERLUCCHI, 2006; SNYDER; SCHMIDT; KINGSTONE, 2009). No entanto, é amplamente reconhecida a consistência com que ele se manifesta comportamentalmente nas mais diferentes condições experimentais (THEEUWES; GODJIN, 2002; LUPIÁÑEZ et al., 2001). Sendo assim, a avaliação do seu efeito poderia fornecer informações importantes sobre o grau de processamento do estímulo precedente pelo sistema nervoso central na condição em que não há demarcação dos locais de aparecimento dos estímulos na tela, caso seja confirmado que as demarcações são de fato importantes para o aparecimento do efeito atencional.

Assim, no experimento A utilizamos uma tarefa de escolha de local com posições demarcadas e no experimento B exatamente a mesma tarefa, mas sem posições demarcadas na tela. As assincronias entre o início dos estímulos são de 100, 400 e 800 milissegundos para que possam ser evidenciados tanto os efeitos característicos da captura atencional como os efeitos característicos da inibição de retorno, caso sejam provocados pelo estímulo precedente. 


\subsection{Material e Métodos}

\subsubsection{Participantes}

Foram selecionados 24 sujeitos com idade entre 18 e 30 anos, destros segundo o questionário de Edinburgh, com visão normal ou corrigida, e com um número de erros abaixo de $10 \%$ do número total de tentativas Os voluntários eram estudantes da Universidade de São Paulo, sem qualquer experiência prévia com esse tipo de teste nem conhecimento dos objetivos do experimento. Seis dos sujeitos eram do sexo masculino e os demais do sexo feminino.

\subsubsection{Material}

As sessões foram realizadas em uma sala ventilada com iluminação reduzida $(<0,1$ $\mathrm{cd} / \mathrm{m}^{2}$ ) e com algum isolamento acústico. Os voluntários foram testados sentados, com a cabeça apoiada em um suporte de testa e queixo e os olhos posicionados a uma distância de aproximadamente $57 \mathrm{~cm}$ da tela de um monitor de vídeo, onde foram apresentados os estímulos visuais.

Sobre a mesa de resposta havia duas chaves interruptoras, uma do lado direito e a outra do lado esquerdo, sobre a quais os voluntários posicionavam seus dedos indicadores. O controle dos estímulos bem como o registro das respostas e o cálculo dos tempos de reação foram feitos por meio de um microcomputador IBM-PC/AT 486 e um programa elaborado com o aplicativo MEL2 (Psychology Software Tools Inc., Pittsburgh, PA, EUA), sendo que a precisão das medidas do tempo de reação foi de $1 \mathrm{~ms}$.

\subsubsection{Procedimento}

\subsubsection{Experimento 1A}


Os voluntários realizaram duas sessões de teste, separadas por no máximo sete dias. A primeira sessão tinha duração média de 10 minutos e a segunda sessão tinha duração média de aproximadamente 30 minutos.

Antes de iniciar cada sessão, os voluntários receberam por escrito as instruções referentes ao testes que realizariam. Estas instruções foram reforçadas na sala de teste. Sob a orientação do experimentador, os voluntários realizaram algumas tentativas como exemplo.

A primeira sessão de teste tinha por objetivo familiarizar o sujeito com as condições experimentais e a seqüência de apresentação dos estímulos era idêntica à da segunda sessão de teste. Os dados dessa primeira sessão não foram submetidos à analise.

$\mathrm{Na}$ segunda sessão de teste foram realizados quatro blocos, cada um com 60 tentativas. Cada tentativa tinha início com o aparecimento de um ponto preto central (ponto de fixação, PF) com luminância de $0 \mathrm{~cd} / \mathrm{m}^{2}$ e dois anéis cinzas (luminância de $3,36 \mathrm{~cd} / \mathrm{m}^{2}, 1,5^{\circ}$ de diâmetro e $0,04^{\circ}$ de borda), cujo centro estava disposto $9^{\circ}$ à esquerda e à direita do $\mathrm{PF}$, em uma tela cinza claro de $15,2 \mathrm{~cd} / \mathrm{m}^{2}$ de luminância. Os anéis cinzas permaneciam na tela durante todas as tentativas, enquanto que o PF desaparecia ao final de cada resposta do voluntário. Após um tempo variável, entre 1850 e 2350 ms, aparecia um estímulo precedente (E1) caracterizado pelo escurecimento da borda de um dos anéis (luminância de $0 \mathrm{~cd} / \mathrm{m}^{2}$, $1,50^{\circ}$ de diâmetro e $0,04^{\circ}$ de borda). Esse estímulo tinha duração de $17 \mathrm{~ms}$ e ocorria em 50\% das tentativas à esquerda e em 50\% das tentativas à direita. Após o desaparecimento do E1, o estímulo alvo (E2) aparecia na tela. O participante deveria responder ao estímulo alvo pressionando o mais rápido possível a chave de resposta com o dedo indicador no lado correspondente ao lado do aparecimento do E2. O E2 era representado por uma linha vertical no interior de um dos anéis (luminância de $0 \mathrm{~cd} / \mathrm{m}^{2}, 0,45^{\circ}$ de comprimento e $0,04^{\circ}$ de borda), durando $34 \mathrm{~ms}$. Ele ocorria na mesma posição (50\% das tentativas) ou na posição oposta (50\% das tentativas) daquela do E1. O intervalo entre o início do E1 e o início do E2 podia ser de 100, 400 ou 800 ms (Figura 1a).

Após cada tentativa aparecia um asterisco verde caso o participante tivesse respondido corretamente, e um asterisco vermelho caso a resposta tivesse sido incorreta. Foram consideradas incorretas respostas com latência menor que $150 \mathrm{~ms}$ ou emitidas antes da apresentação do estímulo precedente (antecipações), respostas com latência maior que $600 \mathrm{~ms}$ (omissões) e respostas dadas com a mão trocada (inversões). As respostas foram consideradas corretas quando dadas ao estímulo alvo estipulado com a mão correspondente ao lado de seu aparecimento. 
Ao final da segunda sessão, todos os participantes foram submetidos ao testes de Acuidade Visual e ao questionário de Edinburgh.

\subsubsection{Experimento 1B}

Diferentemente do Experimento 1A, nesse experimento as posições de aparecimento dos estímulos não foram demarcadas na tela, de modo que no início de cada tentativa só aparecia o ponto de fixação no centro da tela e os estímulos apareciam na tela vazia (Figura 1b) No restante, o procedimento foi idêntico ao do Experimento 1A.

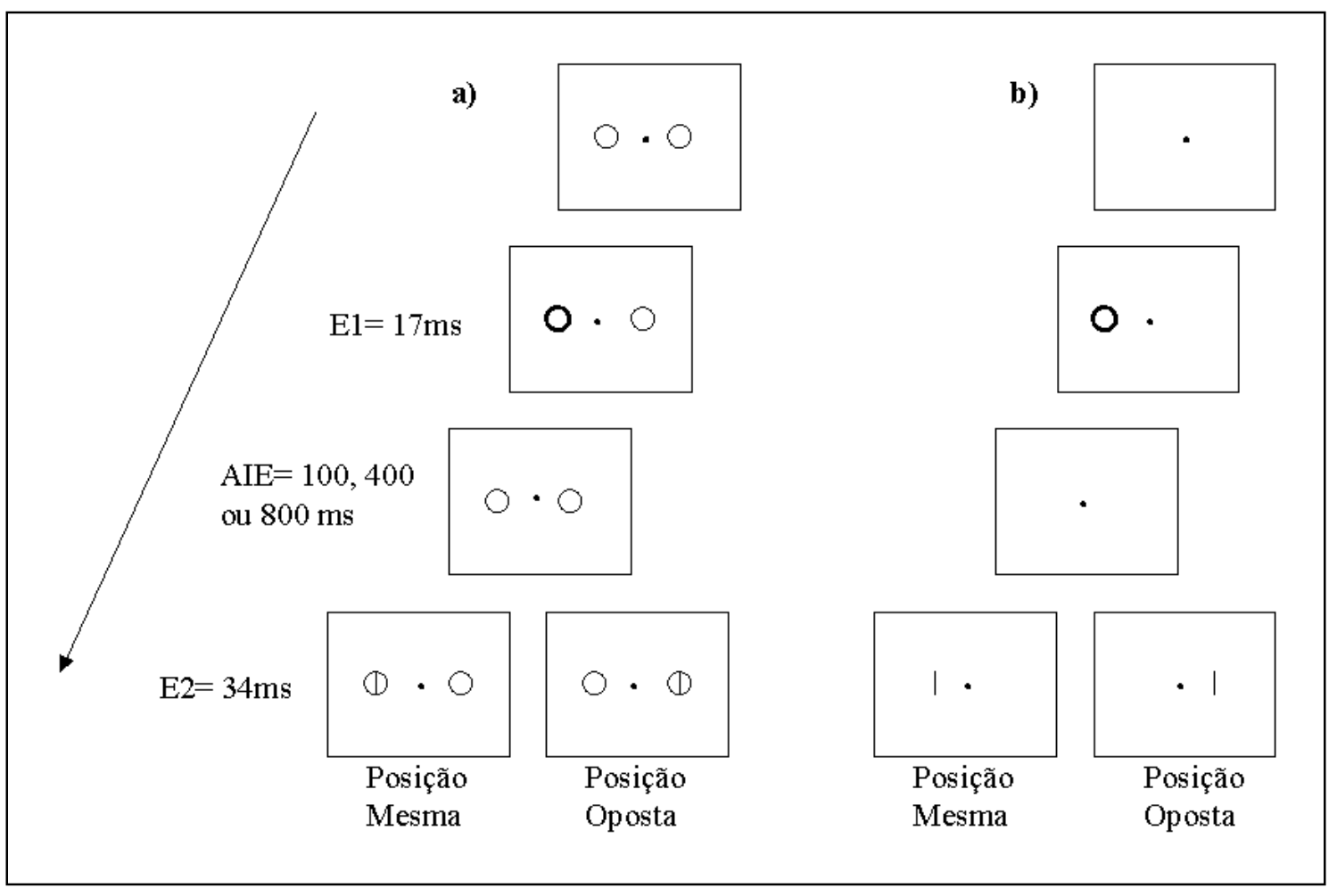

Figura 1: Representação da sequência de apresentação dos estímulos e suas durações. a) Experimento 1A, em que havia demarcações na tela. b) Experimento 1B, em que não havia demarcações na tela. E1: estímulo precedente, AIE: assincronia entre o início dos estímulos precedente e alvo. E2: estímulo alvo.

\subsubsection{Análise de dados}

Para cada voluntário foi calculada a mediana dos tempos de reação em cada bloco da segunda sessão, para então ser feita a média dessas medianas para cada condição. Os dados assim obtidos foram submetidos a uma análise de variância para medidas repetidas. Essa 
análise teve como fatores o grupo (experimento A, com demarcações, e B, sem demarcações), a assincronia entre o início dos estímulos (100, 400 e $800 \mathrm{~ms})$ e a posição do E2 em relação ao E1 (mesma e oposta). Os efeitos que alcançaram probabilidade de erro do tipo I (aceitar como verdadeiro um efeito que é falso) menor ou igual a 0,050 foram aceitos como significativos. Os resultados significativos foram então analisados pelo teste de NewmanKeuls.

A magnitude do efeito atencional do E1 foi calculada subtraindo-se o tempo de reação quando E2 aparecia na mesma posição que E1 do tempo de reação quando o E2 aparecia na posição oposta a de E1. Dessa forma, efeitos positivos caracterizam uma facilitação da resposta e efeitos negativos caracterizam uma inibição da resposta.

\subsection{Resultados e Discussão Parcial}

\subsubsection{Tempos de Reação}

Houve efeito principal para o fator assincronia entre o início dos estímulos $(\mathrm{p}<0,01)$ e interação entre os fatores assincronia entre o início dos estímulos e grupo ( $p<0,01)$, entre os fatores posição de E2 em relação a E1 e grupo $(\mathrm{p}<0,01)$ e entre os fatores assincronia entre o início dos estímulos e posição relativa de E2 em relação a E1 (p<0,01). Não houve interação tripla entre assincronia entre o início dos estímulos, posição relativa de E2 em relação a E1 e grupo $(\mathrm{p}=0,08)$ mas, uma vez que essa interação pode ser considerada marginalmente significativa e houve interação entre o fator grupo e cada um dos demais fatores da análise, fizemos uma análise de variância para medidas repetidas dentro de cada grupo.

A análise de variância do grupo Experimento 1A (com locais demarcados), que teve como fatores a assincronia entre o início dos estímulos e a posição do E2 em relação ao E1 mostrou efeito principal para o fator assincronia entre o início dos estímulos (redução do tempo de reação com o aumento da AIE, $\mathrm{p}<0,01)$, para o fator posição do estímulo alvo em relação ao estímulo precedente ( $p<0,01$ ), e interação entre os dois fatores $(\mathrm{p}<0,01$ ) (Figura 2a). 
A análise post hoc (teste de Newman-Keuls) da interação entre os dois fatores mostrou que os tempos de reação na posição mesma e na posição oposta eram significativamente diferentes quando a assincronia entre o início dos estímulos era de $100 \mathrm{~ms}$ $(\mathrm{p}<0,01)$. Quando a assincronia entre o início dos estímulos era de $400 \mathrm{~ms}$, no entanto, não houve diferença entre os tempos de reação na posição oposta e na posição mesma ( $p=0,12$ ). Quando a assincronia entre o início dos estímulos era de $800 \mathrm{~ms}$, os tempos de reação na posição mesma foram significativamente maiores do que na posição oposta $(p=0,02)$.

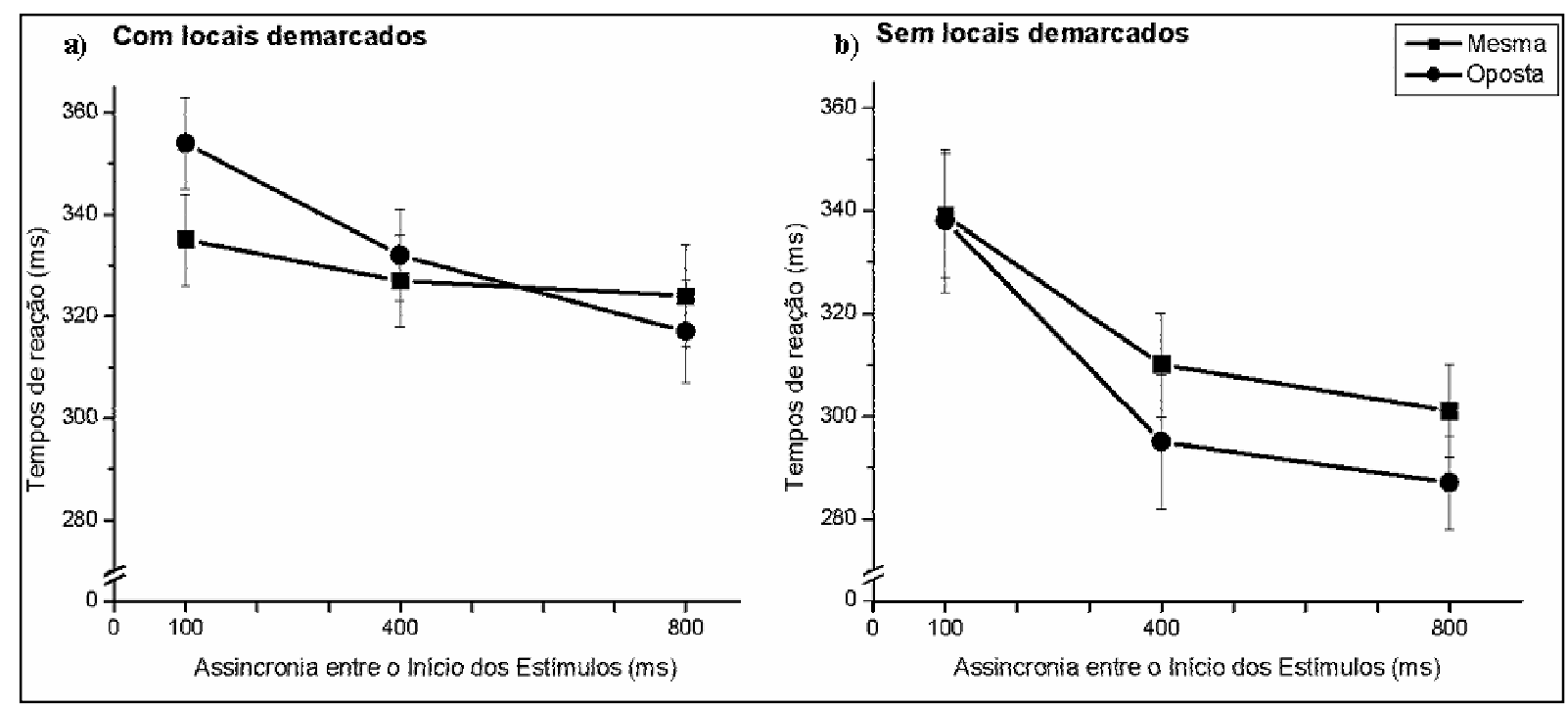

Figura 2: Tempos de reação observados no Experimento 1, na posição mesma (quadrados) e na posição oposta (círculos). a) Experimento 1A, com locais demarcados na tela. b) Experimento 1B, sem locais demarcados na tela.

A análise de variância do grupo Experimento 1B (sem locais demarcados), que teve como fatores a assincronia entre o início dos estímulos e a posição do E2 em relação ao E1 mostrou efeito principal para o fator $\operatorname{AIE}(\mathrm{p}<0,01)$, para o fator posição do estímulo alvo em relação ao estímulo precedente $(\mathrm{p}=0,01)$ (Figura $2 \mathrm{~b})$.

A análise post hoc (teste de Newman-Keuls) da interação entre os dois fatores mostrou que não houve diferença entre os tempos de reação na posição mesma e na posição oposta quando a assincronia entre o início dos estímulos era de $100 \mathrm{~ms}(\mathrm{p}=0,87)$. Quando a assincronia entre o início dos estímulos era de $400 \mathrm{~ms}$ ou de $800 \mathrm{~ms}$, no entanto, houve uma diferença significativa entre os tempos de reação na posição oposta e na posição mesma, com respostas mais lentas na posição mesma do que na posição oposta $(\mathrm{p}<0,01)$. 


\subsubsection{Discussão Parcial}

No Experimento 1A, em que havia demarcações nos locais de aparecimento dos estímulos, encontramos o esperado efeito facilitador do estímulo precedente sobre os tempos de resposta ao estímulo alvo, atribuído à orientação da atenção, na assincronia entre o início dos estímulos de 100 ms. Observamos, também, a inibição de retorno na assincronia entre o início dos estímulos de $800 \mathrm{~ms}$, caracterizada por um atraso no tempo de resposta no local de aparecimento do estímulo precedente. Desse modo, esse desenho experimental reproduz satisfatoriamente o procedimento de Posner e Cohen (1984).

No entanto, no Experimento 1B, em que não havia demarcações nos locais de aparecimento dos estímulos, não houve efeito facilitador na assincronia de $100 \mathrm{~ms}$, mostrando que a presença das demarcações na tela é crítica para a manifestação do efeito atencional nesse procedimento, uma vez que todas os demais parâmetros são idênticos aos utilizados no experimento anterior.

Apesar de não provocar um efeito facilitador sobre a resposta em assincronias curtas, o estímulo precedente foi capaz de provocar, na condição sem demarcações, uma inibição de retorno nas assincronias de 400 e $800 \mathrm{~ms}$.

Os mecanismos neurais responsáveis pela inibição de retorno ainda não são claros, mas estudos recentes têm indicado que se trata de um mecanismo relacionado com áreas corticais importantes, com alguma proximidade e sobreposição com áreas relacionadas com mecanismos atencionais. Lepsien e Pollmann (2002), em um estudo utilizando ressonância magnética funcional, concluíram que a inibição de retorno envolve áreas corticais prémotoras, o giro supra-marginal, e regiões também envolvidas na reorientação da atenção, como o giro frontal medial e o sulco frontal superior posterior esquerdo. Ayabe et al. (2008), em um estudo utilizando magnetoencefalografia, conseguiram medir com alta resolução temporal e espacial as respostas neurais associadas ao aparecimento da inibição de retorno, e sugerem que a junção temporo-parietal bilateral, relacionada com a identificação de eventos salientes no ambiente sensorial, é um substrato neural importante para a inibição de retorno.

Assim, o aparecimento da inibição de retorno no experimento em que não havia demarcações na tela indica que o estímulo precedente, embora não provoque facilitação nessas condições, deve estar sendo processado em níveis suficientes para afetar mecanismos de resposta, causando a inibição de retorno. Não deve, portanto, estar sendo ignorado pelo 
sujeito. De fato, Lamy, Egeth e Leber (2004) e Lamy e Egeth (2003) apresentam evidências de que um estímulo saliente que não tenha atributos relevantes para a tarefa não é ignorado mas sim provoca uma inibição no local de seu aparecimento, levando a respostas mais lentas. Essa é uma explicação possível para o fato de a inibição da resposta no local de aparecimento do estímulo precedente aparecer já em 400 ms quando não há demarcações e apenas em 800 ms quando as demarcações estão presentes.

Theeuwes e Godjin (2002), Schreij, Theeuwes e Olivers (2010) e Folk e Remington (2006) utilizam o aparecimento da inibição de retorno como uma evidência de captura da atenção pelo estímulo precedente. Segundo a linha de argumentação utilizada nesses trabalhos, a inibição de retorno seria um indício de que a atenção teria sido previamente mobilizada para o local de aparecimento do estímulo precedente.

De acordo com a hipótese da inibição de retorno como um fenômeno de inibição do retorno da atenção para um local previamente atendido, a inibição de retorno não seria observada até que a atenção fosse desengajada do local de aparecimento do estímulo precedente. Lupiáñez et al. (2004) e Chica, Lupiáñez e Bartolomeo (2006), utilizando um estímulo periférico informativo válido em $75 \%$ das tentativas, observaram uma inibição de retorno consistente em uma região do espaço onde a atenção estaria alocada, pois essa região era predita por um estímulo periférico informativo. Uma vez que se supõe que, nessa situação, não existe retorno da atenção para o local de aparecimento do estímulo precedente, já que a atenção fica alocada na região predita pela estímulo informativo, não se pode atribuir a inibição de retorno observada à inibição do retorno da atenção para o local de aparecimento do estímulo. Os autores concluíram que o desengajamento da atenção endógena não é uma condição necessária para a observação da inibição de retorno e que a inibição de retorno deve ser um fenômeno automático, independente de modulação de regiões hierarquicamente superiores de processamento. Essa conclusão suporta a linha argumentativa de Theeuwes e Godjin (2002) e Schreij, Theeuwes e Olivers (2010), também utilizada na resposta de Folk e Remington (2006), de que o aparecimento da inibição de retorno indica que a atenção foi capturada previamente para o local de seu aparecimento de maneira puramente automática, sem a influência de modulações de natureza endógena.

Nossos resultados, no entanto, indicam que isso pode não ser necessariamente verdadeiro: a não ser que se postule uma captura atencional automática que tenha ocorrido e desaparecido em até $100 \mathrm{~ms}$, precisamos admitir que um estímulo provoque inibição de retorno em situações em que não ocorreu a captura prévia da atenção, automática ou não. 
Assim como os resultados de Lupiáñez et al. (2004) e Chica, Lupiáñez e Bartolomeo (2006) indicam que a inibição de retorno é um fenômeno independente da orientação endógena da atenção, nossos resultados indicam que a inibição de retorno pode ser um fenômeno independente também da orientação exógena da atenção por um estímulo.

Existem outros estudos que lançam dúvidas sobre essa linha de raciocínio que utiliza a inibição de retorno como evidência da captura prévia, puramente automática, da atenção, defendida por Theeuwes e Godjin (2002). Primeiro, existem evidências na literatura de que a inibição de retorno pode estar sujeita à modulação por processos de natureza endógena. Tipper e Kingstone (2005) discutem essa possibilidade, a partir de um experimento em que a preditibilidade temporal do estímulo precedente é manipulada, e chegam à conclusão de que a inibição de retorno ocorre quando o estímulo precedente é mais relevante para a tarefa e é atenuada conforme a relevância do estímulo precedente é menor. Além disso, existem evidências de que a inibição de retorno e a captura automática da atenção são fenômenos distintos (SNYDER; SCHMIDT; KINGSTONE, 2009; SNYDER; KINGSTONE; SCHMIDT, 2001; GIBSON; AMELIO, 2000), gerados a partir de mecanismos independentes.

Desse modo, embora o aparecimento da inibição de retorno seja um resultado que indica que houve um grau de processamento espacial seletivo gerado pelo estímulo precedente, não permite inferências seguras a respeito da ativação de mecanismos atencionais pelo estímulo precedente. 


\section{EXPERIMENTO 2}

Embora, normalmente, quando um estímulo precedente é capaz de capturar a atenção esse efeito seja observável em uma assincronia de $100 \mathrm{~ms}$ entre o início do estímulo precedente e do estímulo alvo, é possível que esse efeito não seja observado em situações em que tenha ocorrido a captura atencional.

É possível, por exemplo, que um estímulo capture a atenção, mas que a atenção seja rapidamente desengajada do local de seu aparecimento. Essa é uma explicação utilizada por Theeuwes (2010) para a ausência de efeito atencional em algumas situações experimentais.

Outra possibilidade é que o estímulo precedente possa, quando for relativamente intenso, provocar um mascaramento anterógrado que inibe o processamento do alvo, de modo que mesmo que a captura atencional aconteça, ela é anulada por esse efeito inibidor sobre o processamento do estímulo alvo e não é observada no comportamento (KEYSERS; PERRET, 2002; MACNIK; LIVINGSTONE, 1998).

Assim, esse experimento tem o objetivo de examinar com maior detalhe o que ocorre, na variação da tarefa em que não utilizamos demarcações na tela, em assincronias curtas entre o início do estímulo precedente e o início do estímulo alvo. Se o estímulo precedente fosse capaz de capturar a atenção nessa situação, mas a atenção rapidamente se desengajasse do local de seu aparecimento após poucos milissegundos, esse efeito poderia ser observado numa assincronia mais curta. Por outro lado, se um mascaramento anterógrado estivesse impedindo a observação do efeito atencional, esse efeito seria observado numa assincronia mais longa.

\subsection{Material e Métodos}

\subsubsection{Participantes}

Foram selecionados 12 participantes do sexo masculino, com as outras características iguais às descritas no Experimento 1. 


\subsubsection{Material}

Foi utilizado o mesmo material descrito no Experimento 1.

\subsubsection{Procedimento}

O procedimento foi semelhante ao descrito no Experimento 1B, sem demarcações na tela. A única diferença entre o procedimento deste experimento e o procedimento do experimento anterior foi que, no Experimento 1, utilizamos 3 assincronias entre o início da apresentação do estímulo precedente e o início da apresentação do estímulo alvo (100, 400 e $800 \mathrm{~ms}$ ) e, no Experimento 2, utilizamos 5 assincronias entre o início da apresentação do estímulo precedente e o início da apresentação do estímulo alvo, a saber: 50, 100, 150, 200 e $250 \mathrm{~ms}$.

\subsubsection{Análise de dados}

No Experimento 2 foi utilizada a mesma análise de dados descrita no Experimento 1.

\subsection{Resultados e Discussão Parcial}

\subsubsection{Tempo de Reação}

A análise de variância que teve como fatores a assincronia entre o início dos estímulos e a posição do estímulo alvo em relação ao estímulo precedente mostrou efeito principal apenas para o fator assincronia entre o início dos estímulos (Figura 3). Houve uma redução do tempo de reação com o aumento da assincronia $(\mathrm{p}<0,01)$. Não houve efeito principal para o fator posição $(p=0,62)$, nem interação entre os fatores analisados $(p=0,63)$. 


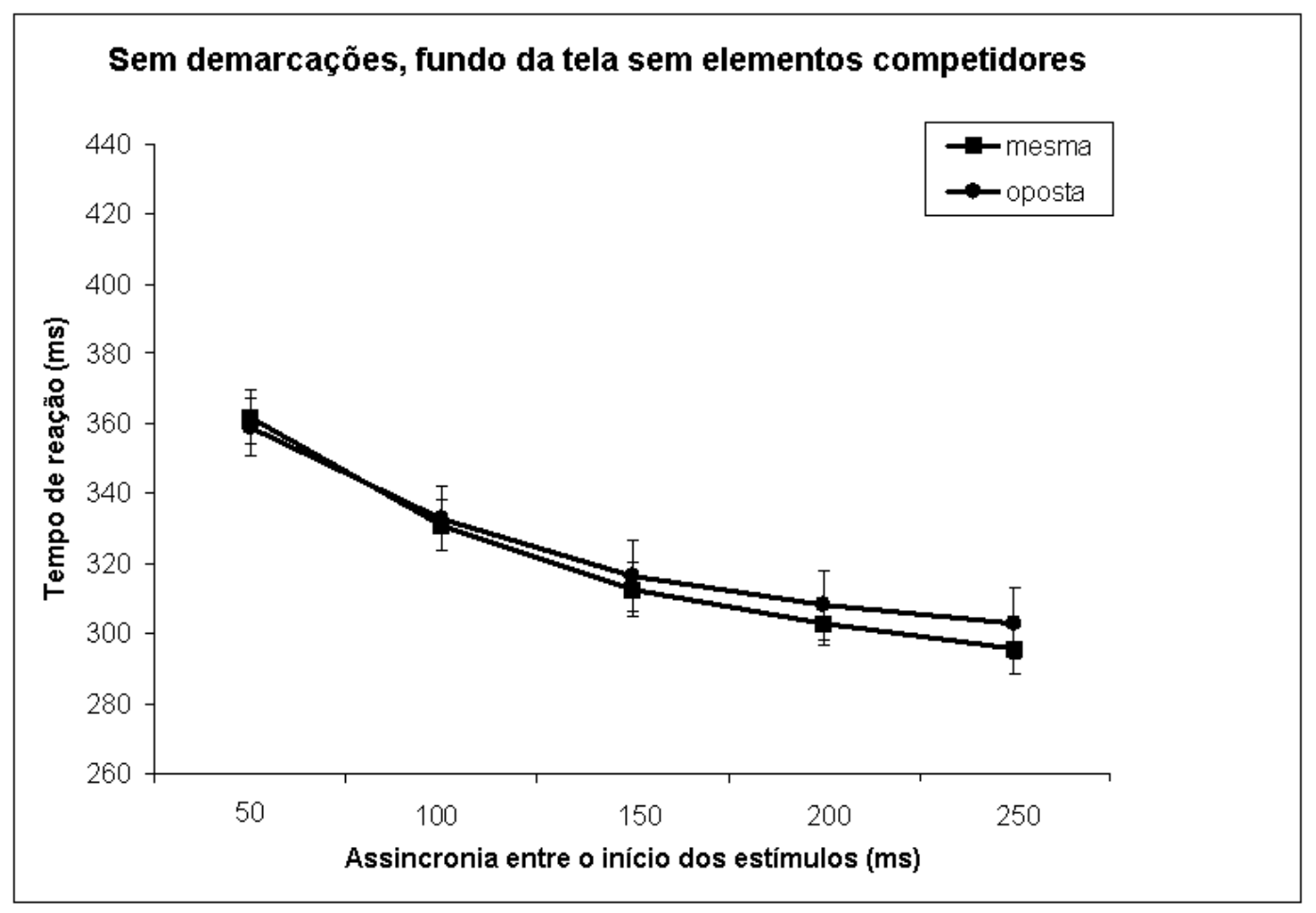

Figura 3: Tempos de reação observados no Experimento 2, na posição mesma (quadrados) e na posição oposta (círculos), nas diferentes assincronias entre o início dos estímulos precedente e alvo.

\subsubsection{Discussão Parcial}

A ausência de efeito atencional observável em uma assincronia mais curta, de $50 \mathrm{~ms}$, torna pouco provável a explicação de que o estímulo precedente possa capturar a atenção quando não são utilizadas demarcações, mas que a atenção seria rapidamente desengajada e por isso não seriam observados os seus efeitos. De fato, a hipótese de que a atenção é sempre capturada por um estímulo saliente, mas pode ser rapidamente desengajada do local de aparecimento desse estímulo em determinadas situações tem poucas evidências a seu favor na literatura atual (LAMY, 2010).

Além disso, uma vez que a captura atencional não foi observada na assincronia de 50 ms, só seria possível explicar a ausência de efeito atencional pela hipótese do rápido desengajamento se fosse considerado que a captura atencional e o desengajamento da atenção já teriam ocorrido em um intervalo tão curto como $50 \mathrm{~ms}$. Nesse caso, seria necessário utilizar 
uma assincronia ainda mais curta para que fosse observado o efeito. Chen e Mordkoff (2007) mostraram ausência de efeito atencional em uma assincronia de $35 \mathrm{~ms}$ quando o estímulo precedente não era relevante para a tarefa. Igualmente, no experimento de Grechi (2006) sem a utilização de demarcações não se observa efeito atencional numa assincronia de 34 ms. Não existem, até onde temos conhecimento, evidências na literatura de uma captura atencional tão rápida e fraca que pudesse durar apenas menos do que aproximadamente $30 \mathrm{~ms}$.

A outra possibilidade testada nesse experimento é que a representação do estímulo precedente, na ausência de demarcações, por representar o aparecimento de um novo objeto e uma mudança de luminância mais intensa do que quando é um aumento de luminância nas demarcações já presentes na tela, poderia estar competindo com a representação do estímulo alvo, provocando um mascaramento anterógrado que impediria a observação do efeito atencional. Entretanto, se isso fosse verdade seria esperado que o efeito atencional fosse observado a partir da assincronia de $200 \mathrm{~ms}$ entre o estímulo precedente e o estímulo alvo (KEYSERS; PERRET, 2002). 


\section{EXPERIMENTO 3}

De acordo com os resultados de Macea et al. (2006), a discriminabilidade do estímulo alvo é um fator crítico para a mobilização da atenção por um estímulo precedente. Assim, em situações em que o alvo é muito discriminável, o estímulo precedente não seria capaz de mobilizar a atenção, e em situações em que o alvo é pouco discriminável o estímulo precedente seria capaz de mobilizar a atenção, mantidos os demais parâmetros.

É possível que as demarcações, normalmente utilizadas em procedimentos adaptados a partir da tarefa de Posner e Cohen (1984), tornem o alvo menos discriminável quando o alvo não for um estímulo muito saliente. Existem evidências de uma competição lateral em neurônios de V1 (KEYSERS; PERRET, 2002; PETROV; McKEE, 2009; POORESMAEILI et al., 2010); em tal competição populações de neurônios que representam os estímulos competidores inibem umas às outras por conexões dentro do mesmo nível de processamento visual. Desse modo, quando outros estímulos presentes na tela, como as demarcações, tiverem uma representação mais intensa do que a representação do estímulo alvo, o estímulo alvo será pouco saliente e, portanto, pouco discriminável. Por outro lado, quando a representação do estímulo alvo for mais intensa do que a representação de outros estímulos, o estímulo alvo será bastante saliente e, portanto, muito discriminável.

A hipótese que testamos neste experimento é que, na situação sem demarcações, não ocorre captura atencional pelo estímulo precedente porque, como não há competição significativa para a representação do estímulo alvo, ele é muito saliente, sendo facilmente discriminável. Já na presença das demarcações, o estímulo precedente captura a atenção porque a representação do estímulo alvo é atenuada, de modo que o estímulo alvo é pouco saliente, mais dificilmente discriminável. Se essa hipótese fosse correta, mantidos todos os demais parâmetros utilizamos no experimento sem posições demarcadas, o estímulo precedente deveria capturar a atenção desde que houvesse estímulos competidores na tela que pudessem atenuar a representação do estímulo alvo, tornando-o menos saliente e, portanto, menos discriminável.

\subsection{Material e Métodos}




\subsubsection{Participantes}

Foram selecionados 8 sujeitos do sexo feminino e 4 sujeitos do sexo masculino, com as outras características iguais às descritas no Experimento 2.

\subsubsection{Material}

Foi utilizado o mesmo material descrito no Experimento 2.

\subsubsection{Procedimento}

O procedimento foi idêntico ao descrito no Experimento 2, mas neste experimento foram adicionadas 8 linhas horizontais e 11 linhas verticais na tela, formando um padrão quadriculado de fundo $\left(2,5^{\circ}\right.$ por $2,5^{\circ}$ ). As linhas tinham luminância de $3,4 \mathrm{~cd} / \mathrm{m}^{2}$ (mesma luminância das demarcações do experimento 1A), espessura de $0,04^{\circ}$ e o mesmo comprimento da tela.

\subsubsection{Análise de dados}

No Experimento 3 foi utilizada a mesma análise de dados descrita no Experimento 2.

\subsection{Resultados e Discussão Parcial}

\subsubsection{Tempo de Reação}

A análise de variância que teve como fatores a assincronia entre o início dos estímulos e a posição do estímulo alvo em relação ao estímulo precedente mostrou efeito principal para o fator assincronia entre o início dos estímulos e para o fator posição (Figura 4). 
Houve uma redução do tempo de reação com o aumento da assincronia ( $p<0,01)$. Houve efeito principal para o fator posição relativa entre o estímulo precedente e o estímulo alvo $(\mathrm{p}=$ $0,03)$. Não houve interação entre os dois fatores $(p=0,37)$.

A análise post-hoc com o teste de Neuman-Keuls mostrou que não há diferença entre os tempos de reação na posição mesma e na posição oposta nas assincronias de $50 \mathrm{~ms}(\mathrm{p}=$ 0,06) e que há diferença nas assincronias de $100 \mathrm{~ms}(\mathrm{p}=0,02), 150 \mathrm{~ms}(\mathrm{p}<0,01), 200 \mathrm{~ms}(\mathrm{p}$ $<0,01)$ e $250 \mathrm{~ms}(\mathrm{p}<0,01)$.

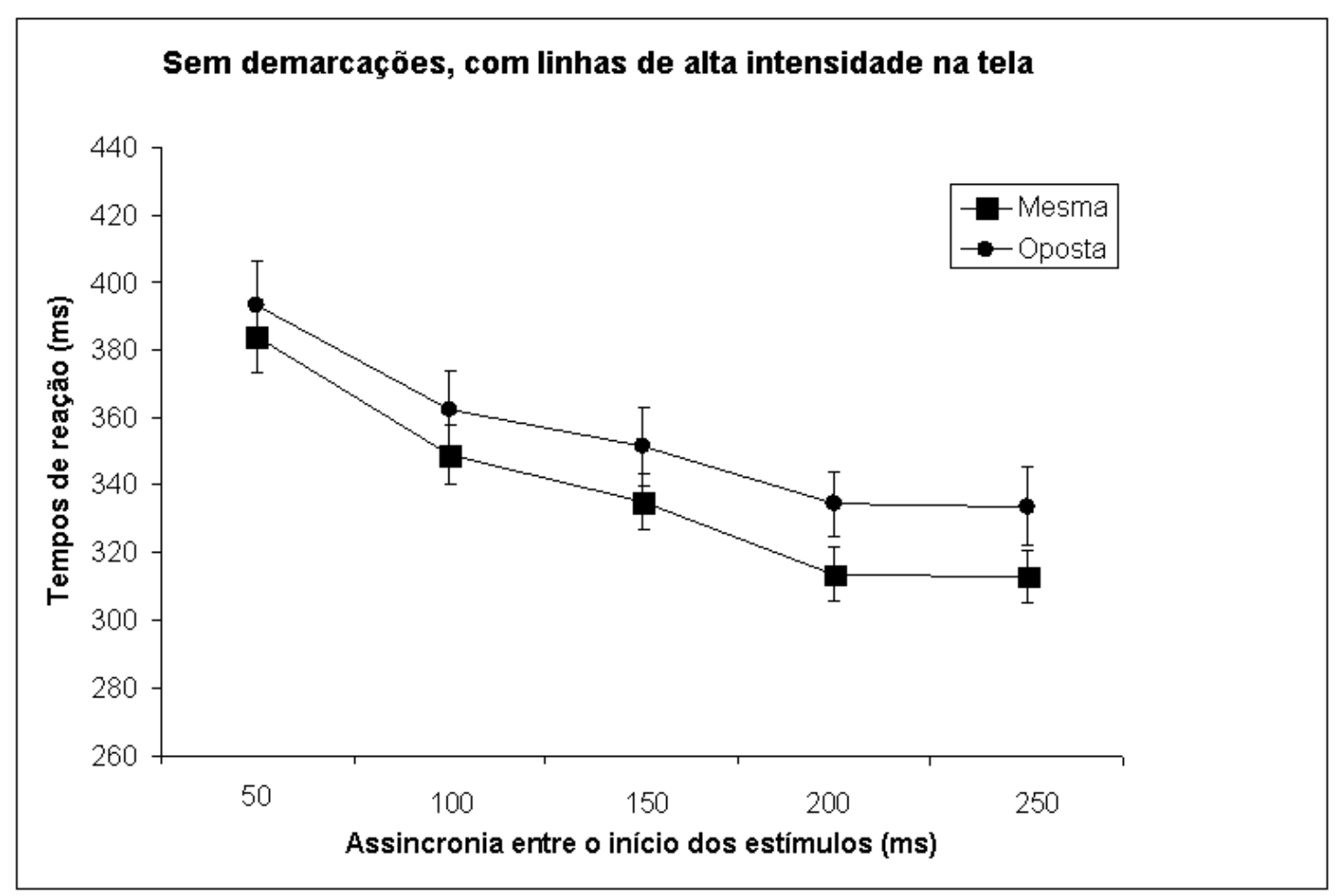

Figura 4: Tempos de reação obtidos no Experimento 3, em que não havia demarcações na tela, mas havia linhas horizontais e verticais de alta intensidade distribuídas ao longo da tela. Os tempos de reação na posição mesma estão indicados pelos quadrados e os tempos na posição oposta estão indicados pelos círculos.

\subsubsection{Discussão Parcial}

A observação de um efeito atencional significativo nas assincronias de 100, 150, 200 e 250 ms está de acordo com com a hipótese de que a saliência do estímulo alvo pode 
modular as configurações atencionais do sujeito, permitindo ou não a captura da atenção por um estímulo precedente.

Essa hipótese é compatível com a teoria da captura contingente da atenção de Folk e Remington. (1992), segundo a qual a captura atencional é modulada de acordo com os atributos dos estímulos precedente e alvo, embora não considere a semelhança explícita entre o estímulo precedente e o estímulo alvo como um fator crítico. Podemos considerar que, quando existem estímulos competidores apresentados simultaneamente na tela, estes adicionariam ruído ao processamento dos estímulos precedente e alvo. Se os estímulos competidores tiverem uma representação mais intensa do que as representações dos estímulos precedente e alvo, ou seja, se o ruído no processamento desses dois estímulos for suficientemente alto, a distinção entre o estímulo precedente e o estímulo alvo pode ser reduzida na representação neural dos mesmos. Desse modo, é como se o sistema nervoso os considerasse mais semelhantes nessas condições do que numa situação em que ambos os estímulos são processados na ausência de estímulos competidores.

Se essa hipótese for verdadeira, diminuindo-se a intensidade das linhas horizontais e verticais utilizadas como fundo de tela nesse experimento, esperaríamos que o estímulo precedente não capturasse a atenção, mantidos os demais parâmetros. 


\section{EXPERIMENTO 4}

Esse experimento teve por objetivo corroborar a hipótese de que, de fato, a discriminabilidade do estímulo alvo é um fator que pode modular a captura atencional por um estímulo precedente, e se essa discriminabilidade poderia ser alterada pela intensidade da representação de estímulos competidores. Para isso, repetimos o experimento anterior, reduzindo a intensidade das linhas horizontais e verticais apresentadas como fundo da tela. Esperávamos que, nessas condições, o estímulo precedente não capturasse a atenção.

Além disso, Woodman, Arita e Luck (2009) propuseram que demarcações são importantes por proporcionarem um objeto que serve de âncora para focalizar a atenção, em uma tarefa de orientação voluntária da atenção. Essa hipótese poderia explicar os nossos resultados até então, uma vez que os quadrados de fundo da tela poderiam funcionar com objetos tal como as demarcações utilizadas classicamente. No entanto, se isso fosse verdade, esperaríamos que fosse observado um efeito atencional no presente experimento, uma vez que os quadrados continuam presentes na tela, apenas percebidos com menor intensidade do que no experimento anterior.

\subsection{Material e Métodos}

\subsubsection{Participantes}

Foram selecionados 8 sujeitos do sexo feminino e 4 sujeitos do sexo masculino, com as outras características iguais às descritas no Experimento 3.

\subsubsection{Material}

Foi utilizado o mesmo material descrito no Experimento 3. 


\subsubsection{Procedimento}

O procedimento foi idêntico ao descrito no Experimento 3, exceto pelo fato de que, nesse experimento, a luminância das linhas horizontais e verticais utilizadas como fundo da tela era de $13,5 \mathrm{~cd} / \mathrm{m}^{2}$, mais próxima à luminância do fundo, de modo que elas eram percebidas como linhas mais fracas pelos sujeitos.

\subsubsection{Análise de dados}

No Experimento 4 foi utilizada a mesma análise de dados descrita no Experimento 3.

\subsection{Resultados e Discussão Parcial}

\subsubsection{Tempo de Reação}

A análise de variância que teve como fatores a assincronia entre o início dos estímulos e a posição do estímulo alvo em relação ao estímulo precedente mostrou efeito principal apenas para o fator assincronia entre o início dos estímulos (Figura 5). Houve uma redução do tempo de reação com o aumento da assincronia $(\mathrm{p}<0,01)$. Não houve efeito principal para o fator posição $(p=0,17)$, nem interação entre os fatores analisados $(p=0,60)$.

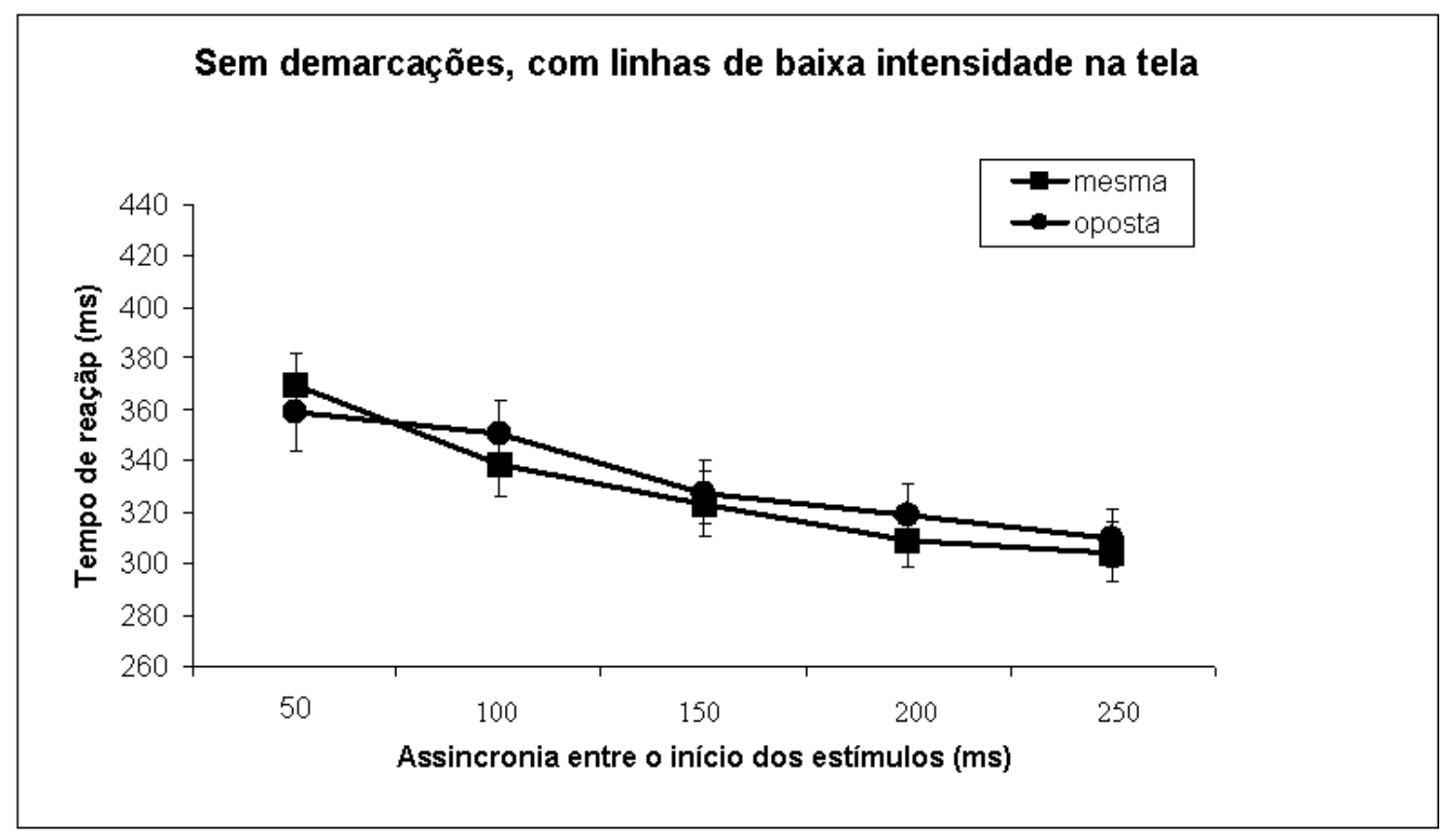

Figura 5: Tempos de reação obtidos no Experimento 4, em que havia linhas de baixa intensidade no fundo da tela, na posição mesma (quadrados) e oposta (círculos). 


\subsubsection{Discussão Parcial}

O fato de não observarmos nenhum efeito comportamental da captura da atenção pelo estímulo precedente nesse experimento corrobora a nossa predição de que a intensidade dos estímulos competidores pode alterar a discriminabilidade dos estímulos, tornando-os menos distintos e levando à captura atencional pelo estímulo precedente mesmo que este não tenha uma semelhança física explícita com o estímulo alvo. Uma vez que a informação espacial e a presença de objetos que pudessem funcionar como âncora para a focalização da atenção foram mantidos inalterados, não se pode atribuir a captura atencional a esses fatores.

Stokes et al. (2009) mostraram uma ativação seletiva de populações de neurônios associadas a um estímulo alvo no complexo occipital lateral, onde ocorre o processamento de formas, logo após a apresentação de uma pista atencional. Os autores concluíram que as configurações atencionais determinadas pelos objetivos do sujeito podem facilitar representações de estímulos relevantes para a tarefa, e observaram que essa representação é mantida ativa durante toda a tentativa. Pode-se imaginar que representações de estímulos relevantes estejam presentes a todo o momento em outras tarefas realizadas pelo sujeito. Numa tarefa adaptada de Posner como a que utilizamos, por exemplo, a partir do início da tentativa o sujeito possivelmente mantém ativadas representações do estímulo alvo, que deve surgir dentro de um intervalo razoavelmente previsível a partir do aparecimento do ponto de fixação indicando o início da tentativa. Assim, quando o estímulo precedente e o estímulo alvo tiverem representações pouco distintas entre si (o que imaginamos que ocorra quando o estímulo alvo é pouco discriminável), o estímulo precedente é considerado compatível com a representação ativada e, portanto, relevante para a tarefa, de modo que captura a atenção para o local de seu aparecimento.

Essa hipótese para explicar a importância das demarcações como estímulos competidores que reduzem a discriminabilidade do estímulo alvo, está de acordo com o modelo proposto por Lu e Dosher (1998, 2000), segundo o qual a magnitude do efeito atencional depende da quantidade de ruído no local em que está inserido o estímulo alvo, além de explicar a captura contingente da atenção por um estímulo precedente quando este compartilha uma característica física com o estímulo alvo. É, portanto, uma descrição relativamente abrangente do fenômeno que permite interpretar resultados do nosso laboratório e também um conjunto de diferentes resultados da literatura em que se demonstra que a captura atencional é modulada pelas configurações atencionais determinadas pela tarefa. 
Existem evidências eletrofisiológicas de que um contexto que altere a facilidade ou dificuldade de discriminação de um estímulo alvo pode modular o processamento do demais estímulos apresentados. Sawaki e Katayama (2009), estudando a mobilização atencional por estímulos pouco frequentes, mostraram que a dificuldade de discriminação entre um estímulo alvo pouco frequente e um estímulo padrão frequente pode modular a focalização da atenção e a captura atencional por um estímulo distraidor pouco frequente. De acordo com os autores, quando a discriminação do estímulo alvo é difícil, a atenção é focalizada e o um estímulo distrator que seja apresentado fora do foco atencional não mobiliza o processamento atencional. Por outro lado, quando o estímulo distrator é apresentado dentro do foco atencional, mobiliza o processamento atencional.

É possível que a dificuldade de discriminação do estímulo alvo atue de forma análoga sobre a mobilização de mecanismos atencionais por um estímulo irrelevante quando os estímulo alvo e o estímulo distraidor forem estímulos frequentes. Uma vez que na nossa tarefa o estímulo precedente e o estímulo alvo aparecem sempre nos mesmos locais, à direita ou à esquerda do ponto de fixação, a dificuldade de discriminação do estímulo alvo pode focalizar a atenção na região de aparecimento dos estímulos. Assim, quando são utilizadas demarcações ou o fundo quadriculado com linhas intensas, a discriminação do estímulo alvo é mais difícil e, uma vez que o estímulo precedente seja apresentado dentro desse foco atencional, mobiliza o processamento atencional para o local de seu aparecimento. Por outro lado, quando o estímulo alvo aparece na tela vazia ou na tela com o fundo quadriculado com linhas pouco intensas, a discriminação do estímulo alvo é mais fácil, o que tornaria a atenção menos focalizada. 


\section{EXPERIMENTO 5}

Lupiánez et al. (2001) mostraram que o curso temporal da facilitação atencional e da inibição de retorno podem depender da natureza da tarefa: a inibição de retorno, segundo os autores, costuma aparecer mais tardiamente em tarefas que exigem discriminação do que em tarefas que exigem apenas a detecção do estímulo alvo. Os autores defendem que existe uma interação entre os sistemas atencionais exógenos e endógenos e que, portanto, a captura da atenção por um estímulo pode ser modulada de acordo com a demanda da tarefa. Assim, é possível que, caso fosse necessário fazer uma discriminação mais difícil para responder ao alvo, em vez de apenas detectar o local de seu aparecimento, o efeito atencional aparecesse mesmo sem a utilização de demarcações na tela.

Neste experimento, utilizamos uma tarefa de discriminação de forma. No experimento $5 \mathrm{~A}$ foram utilizadas demarcações na tela e no experimento $5 \mathrm{~B}$ não foram utilizadas demarcações na tela. Nosso objetivo era verificar se os efeitos observados no Experimento 1A e 1B são replicados ou se a necessidade de discriminar entre dois alvos diferentes pode modular de maneira diferente a captura atencional e a inibição de retorno. Caso os resultados fossem mantidos, poderíamos inferir que a discriminabilidade do estímulo alvo é um fator que pode modular a captura atencional por um estímulo precedente tanto em tarefas de escolha de local como em tarefas de discriminação de forma, de modo que as hipóteses aqui discutidas podem ter um caráter mais abrangente.

\subsection{Material e Métodos}

\subsubsection{Participantes}

Foram selecionados 12 sujeitos para o experimento 5A e 12 sujeitos para o experimento 5B, com características idênticas à dos experimentos anteriores.

\subsubsection{Material}


Foi utilizado o mesmo material descrito nos experimentos anteriores.

\subsubsection{Procedimento}

O procedimento foi idêntico ao descrito nos Experimentos $1 \mathrm{~A}$ e $1 \mathrm{~B}$, exceto pelo fato de que, nesse experimento, foram apresentados dois alvos diferentes: uma linha vertical idêntica à utilizada com estímulo alvo nos experimentos anteriores e também um anel com mesma luminância e borda utilizados na linha vertical e com $0,29^{\circ}$ de diâmetro. Os participantes deveriam responder para a figura, utilizando uma das mãos para responder para a linha vertical e a outra mão para responder para o anel. Metade dos voluntários em cada experimento deveria utilizar a mão esquerda para responder à linha vertical e a mão direita para responder ao anel e a outra metade deveria utilizar a mão esquerda para responder ao anel e a mão direita para responder à linha vertical.

\subsubsection{Análise de dados}

No Experimento 5 foi utilizada a mesma análise de dados descrita no Experimento 1.

\subsection{Resultados e Discussão Parcial}

\subsubsection{Tempo de Reação}

A análise de variância considerando todos os grupos conjuntamente, com e sem demarcação e todas as possibilidades de combinação entre a mão de resposta e o tipo de alvo, tendo como fatores o grupo, a assincronia entre o início dos estímulos e a posição do E2 em relação ao E1 mostrou efeito principal apenas para o fator assincronia entre o início dos estímulos $(\mathrm{p}<0,01)$. Não há diferenças entre os grupos com e sem demarcação.

No entanto, uma vez que estava planejada no desenho inicial do experimento a comparação entre os resultados para o grupo em que havia posições demarcadas e os 
resultados para o grupo em que não havia posições demarcadas, fizemos uma análise de variância separada para cada um desses grupos, de modo a avaliar mais detalhadamente os tempos de reação em cada uma das duas condições.

A análise de variância considerando apenas os resultados do grupo em que havia posições demarcadas teve como fatores o grupo (de acordo com a mão de resposta para cada estímulo alvo), a assincronia entre o início dos estímulos e a posição do E2 em relação ao E1. Houve efeito principal para o fator AIE $(p<0,01)$ e para o fator condição $(p<0,05)$. Houve interação entre os dois fatores $(\mathrm{p}<0,05)$. Assim, não houve diferença para mão de resposta utilizada para cada estímulo, mas houve diferença entre as respostas na condição mesma e na condição oposta e essa diferença está relacionada com a assincronia entre o início dos estímulos (Figura 6a).

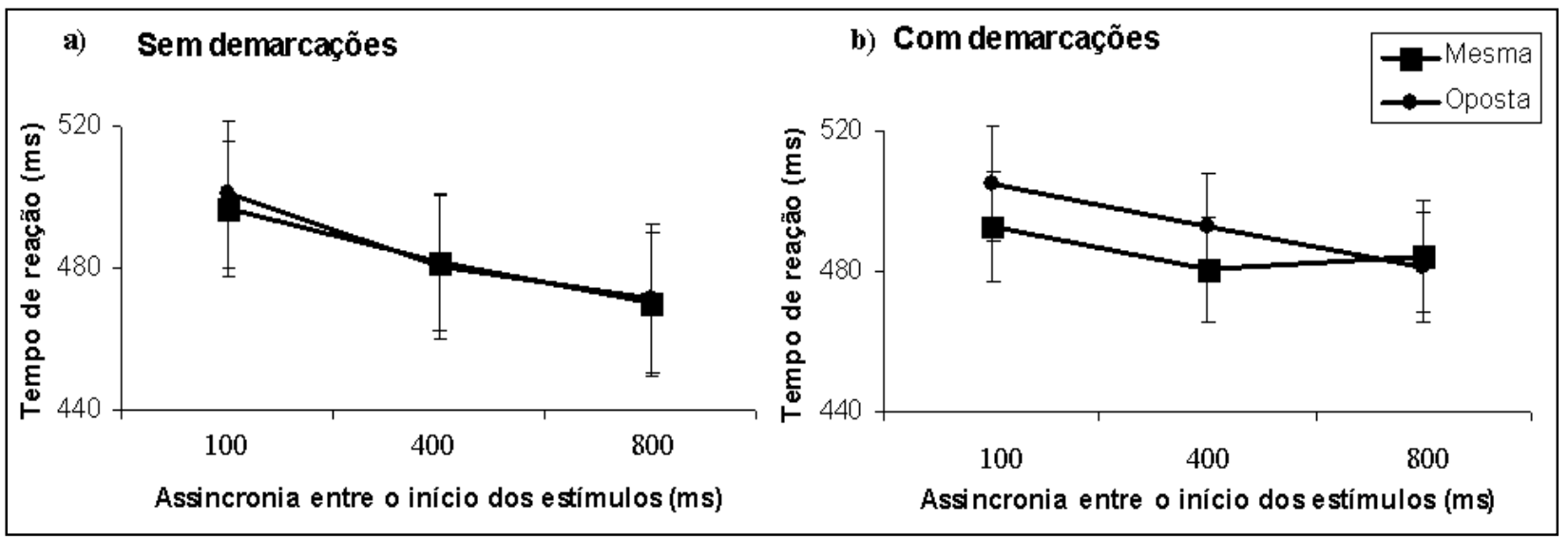

Figura 6: Tempos de reação obtidos no Experimento 5, em uma tarefa de discriminação de forma, na posição mesma (quadrados) e na posição oposta (círculos). a) Experimento 5A, com locais demarcados. b) Experimento 5B, sem locais demarcados.

A análise post hoc (teste de Newman-Keuls) da interação entre os dois fatores mostrou que houve uma diferença marginalmente significativa entre as condições mesma e oposta quando a assincronia entre o início dos estímulos era de $100 \mathrm{~ms}(\mathrm{p}=0,08)$. Esta análise também mostrou uma diferença significativa entre o tempo de reação na condição oposta na assincronia de 100 ms e todos os outros tempos de reação observados nas demais assincronias $(\mathrm{p}<0,05)$.

A análise de variância considerando apenas os resultados do grupo em que não havia posições demarcadas teve como fatores o grupo (de acordo com a mão de resposta para cada estímulo alvo), a assincronia entre o início dos estímulos e a posição do E2 em relação ao E1. 
Houve efeito principal para o fator $\operatorname{AIE}(\mathrm{p}<0,01)$. Não houve diferença entre os dos grupos ou entre a condição mesma e a condição oposta (Figura 6b).

A análise post hoc (teste de Newman-Keuls) do fator AIE mostrou que os tempos de reação na assincronia de $100 \mathrm{~ms}$ são significativamente diferentes dos tempos de reação nas assincronias de 400 e de 800 m (p<0,05). Não há diferença significativa entre os tempos de reação nas assincronias de 400 e de 800 ms.

\subsubsection{Discussão Parcial}

Embora não exista interação entre o grupo em que havia posições demarcadas e o grupo em que não havia posições demarcadas, quando fazemos a análise separadamente para esses dois grupos temos um padrão diferente nos resultados em cada uma dessas situações. Assim, verificamos que existe, no grupo em que há posições demarcadas na tela, uma diferença marginalmente significativa entre as condições mesma e oposta quando a assincronia entre o início dos estímulos era de 100 ms. Existe, portanto, uma tendência para o aparecimento do efeito atencional nessa condição, embora ele não seja tão evidente como no experimento $1 \mathrm{~A}$, em que a tarefa era de escolha de local.

Posner, Snyder e Davidson (1980) observaram que a magnitude do efeito atencional em uma tarefa em que era necessário identificar o estímulo alvo e escolher a mão de resposta era visivelmente menor do que a magnitude do efeito atencional em uma tarefa em que era necessário apenas detectar o aparecimento do estímulo alvo. Os autores atribuem essa diferença à necessidade de o sujeito desviar a atenção da região espacial indicada pelo estímulo precedente para processos internos realizados para identificar o estímulo alvo e discriminar a resposta adequada. Essa é uma explicação possível para que no Experimento 5A tenhamos obtido um efeito atencional marginalmente significativo, enquanto no Experimento 1A esse efeito foi significativo. Nesse caso, um efeito menor na tarefa de discriminação resultaria em uma diferença apenas marginalmente significativa porque essa diferença seria mais afetada pela variabilidade natural na manifestação do comportamento.

Outra explicação é que a variabilidade dos dados na tarefa de discriminação afete mais acentuadamente o resultado da análise estatística devido ao maior número de fatores presentes na análise, ou mesmo que a variabilidade dos dados seja maior nesse experimento devido ao maior número de condições experimentais utilizadas. Se isso for verdade, 
aumentando o número de sujeitos provavelmente os efeitos observados na tarefa de discriminação de forma do Experimento 5A seriam semelhantes aos efeitos observados na tarefa de escolha de local do Experimento 1A. 


\section{DISCUSSÃO GERAL}

Observamos que alterações na tela em que aparecem os estímulos podem determinar se observamos no comportamento o efeito da captura atencional pelo estímulo precedente. Levando em consideração o conjunto dos experimentos apresentados, a existência de uma competição significativa pelo processamento dos estímulos parece ser o fator crítico para o aparecimento do efeito. Quando existem demarcações ou linhas distribuídas na tela com a mesma intensidade do estímulo alvo, o efeito da captura atencional aparece. Por outro lado, quando a tela em que aparecem os estímulos é vazia ou tem linhas de intensidade consideravelmente mais baixa que a intensidade do estímulo alvo, o efeito da captura atencional não aparece.

Na primeira situação, em que os estímulos precedente e alvo aparecem na presença de estímulos com os quais ocorre uma competição significativa no processamento sensorial, os estímulos precedente e alvo são menos salientes. Nesse caso, podemos dizer que o processamento dos estímulos precedente e alvo não é muito distinto, em termos das redes neuronais ativas na representação de cada estímulo. Na segunda situação, em que os estímulos precedente e alvo aparecem em uma tela vazia, sem que haja outros estímulos competidores pelo processamento sensorial, os estímulos precedente e alvo são mais salientes. Nesse caso, podemos dizer que o processamento dos estímulos é mais distinto, em termos das redes neuronais ativas na representação de cada estímulo. O fator crítico para o aparecimento do efeito da captura atencional por um estímulo precedente seria, portanto, o grau de sobreposição entre as redes neuronais que representam o estímulo precedente e as redes neuronais que representam o estímulo alvo de interesse para o sujeito realizar a tarefa.

Se assumirmos que a ausência do efeito atencional significa que o estímulo precedente não capturou a atenção, o grau de sobreposição entre as redes neuronais pode ser importante porque, quando ocorre alguma sobreposição entre essas representações, o estímulo precedente, ao aparecer na tela, capturaria a atenção e deixaria parcialmente facilitada a representação do estímulo alvo. Posteriormente, quando o estímulo alvo aparece na tela, seu processamento seria mais eficiente, devido a essa ativação prévia.

Uma outra possibilidade para explicar a ausência do efeito atencional é que o estímulo precedente tenha capturado a atenção, mobilizando mecanismos de facilitação, mas 
que o efeito de ativação desses mecanismos não tenha sido observado no comportamento. De acordo com essa explicação, quando o estímulo alvo é saliente, o seu processamento e a resposta ao seu aparecimento, estão otimizados ao máximo, de modo que a captura atencional não leva a uma melhora significativa na performance. Nesse caso, as redes neuronais que representam o estímulo alvo seriam tão fortemente ativadas pelo aparecimento do estímulo alvo, que uma facilitação adicional por outros neurônios não seria capaz de aumentar a frequência ou a duração dos seus disparos

Nós acreditamos que a primeira possibilidade, de que a ausência de efeito atencional significa que o estímulo precedente de fato não ativou mecanismos atencionais, é a mais adequada para o conjunto de resultados que apresentamos nesse trabalho. Argumentos tanto de natureza fisiológica como de natureza filosófica nos levam a adotar essa posição.

Tipicamente, quando se faz registros de eletroencefalograma associados a tarefas comportamentais como as tarefas que foram realizadas pelos sujeitos no presente estudo, a ausência do efeito da captura atencional no comportamento é acompanhada por uma ausência desse efeito também no registro eletrofisiológico (EIMER; KISS, 2008; EIMER et al., 2009).

Eimer e Kiss (2008) realizaram dois experimentos adaptados a partir dos experimentos de Folk et al. (1992) e registraram os dados comportamentais e do eletroencefalograma. No primeiro experimento, um estímulo alvo a que os voluntários deveriam responder era uma barra que se tornava vermelha, apresentada em meio a barras cinzas. Os voluntários deveriam reportar a orientação da barra alvo. Esses dados foram comparados aos dados quando o estímulo alvo era o aparecimento de uma barra cinza, cuja orientação deveria ser reportada pelos voluntários. O estímulo precedente utilizado, não informativo espacialmente, era a mudança de cor de um dos quatro pontos que marcava os possíveis locais de aparecimento do estímulo alvo. Foi observado o efeito comportamental da captura da atenção pelo estímulo precedente quando o alvo era a mudança de cor de uma das barras cinzas, mas não quando o estímulo alvo era o aparecimento de uma barra cinza. E, igualmente, na análise do registro do eletroencefalograma dos voluntários, o componente $\mathrm{N} 2 \mathrm{pc}$, indicativo da captura da atenção, estava presente na situação em que se observou o efeito da captura atencional no comportamento, mas não estava presente na situação em que esse efeito não foi observado no comportamento. Uma vez que a presença do N2pc parece refletir a seleção atencional de um estímulo e também o processamento específico de características dos estímulos em locais do espaço potencialmente relevantes para a tarefa 
previamente à seleção do estímulo alvo (KISS; VELZEN; EIMER, 2008), esse resultado é difícil de ser explicado, a não ser pela hipótese de que o estímulo precedente capturou a atenção em uma condição, mas não capturou na outra. Poder-se-ia argumentar que Eimer e Kiss (2010) mostraram, numa situação em que não ocorre o efeito comportamental da captura da atenção, o componente N2pc está presente. Mas, embora o componente N2pc esteja presente, ele está atrasado e atenuado, o que está de acordo com a hipótese de que existe uma correlação entre a ativação de mecanismos atencionais e os efeitos comportamentais observados, mesmo que essa relação não seja do tipo tudo-ou-nada.

Um argumento adicional a favor da suposição de que a ausência de efeito atencional no comportamento significa que o estímulo precedente não ativou mecanismos atencionais é que essa explicação dá conta de um maior número de resultados semelhantes aos nossos encontrados na literatura e obtidos anteriormente em nosso laboratório.

Os trabalhos de Folk e colaboradores apresentam resultados em que ocorre uma facilitação na resposta ao estímulo alvo quando o estímulo precedente tem alguma semelhança física com o estímulo alvo, mas quando o estímulo precedente e o estímulo alvo não possuem nenhuma semelhança física não ocorre essa facilitação na resposta ao estímulo alvo. Esses resultados não podem ser explicados pela hipótese de que o estímulo precedente teria ativado mecanismos atencionais mas os efeitos não teriam sido observados porque o processamento do estímulo alvo estaria otimizado ao máximo. Eles só podem ser explicados por uma hipótese que considere a relação entre os estímulos apresentados durante a realização de uma tarefa.

Em nosso laboratório temos resultados anteriores (MACEA et al., 2006), de uma tarefa vai-não-vai, com dois tipos de estímulo alvo, um estímulo alvo positivo, a que o sujeito deve responder, e um estímulo alvo negativo, a que o sujeito não deve responder. Nessa tarefa, a relação entre o estímulo alvo positivo e o estímulo alvo negativo se mostrou determinante para o aparecimento ou não do efeito da captura atencional. Quando o estímulo alvo positivo e o estímulo alvo negativo são pouco distintos entre si, o efeito da captura atencional aparece. Quando o estímulo alvo positivo e o estímulo alvo negativo são muito distintos entre si, não é observado nenhum efeito de facilitação da resposta ao estímulo alvo positivo. Esse resultado não pode ser explicado pela hipótese de que o estímulo precedente captura a a atenção, mas não se observa efeito devido a um processamento já maximamente eficiente do alvo positivo, uma vez que o alvo positivo é o mesmo em ambas as situações. 
Esse resultado pode, no entanto, ser explicado pela nossa hipótese, de acordo com a qual qualquer condição que torne menos específica a representação do estímulo de interesse ativada durante a realização da tarefa favorece a sobreposição de redes neuronais que representam os estímulos visuais apresentados na cena visual e, portanto, levam a uma captura da atenção pelo estímulo precedente.

Assim, embora existam duas explicações possíveis para o conjunto de resultados apresentado neste trabalho, a hipótese de que não observamos o efeito da captura atencional nos experimentos 1B, 2 e 4 porque a atenção não foi capturada pelo estímulo precedente é mais abrangente do que a hipótese de que o estímulo precedente capturou a atenção nesses experimentos, mas não observamos os efeitos dessa captura porque o processamento do estímulo alvo estava otimizado ao máximo nessas condições. Consideramos preferível escolher uma hipótese que dá conta de explicar um maior número de fenômenos em condições similares do que adotar explicações diferentes para cada situação particular, por ser uma maneira mais parcimoniosa de explicar um determinado conjunto de fenômenos.

Além disso, postular a existência de um efeito que não é observado tem o problema de ser um pressuposto relativamente difícil de ser falseado: poder-se-ia elaborar uma série infindável de explicações para que as evidências do fenômeno não estivessem sendo observadas em diferentes situações. Por outro lado, a hipótese de que a ausência de efeito atencional ocorre porque a atenção não foi capturada pelo estímulo precedente seria relativamente mais fácil de ser falseada, com a realização de registros eletrofisiológicos ou de neuroimagem nas condições em que o efeito não aparece no comportamento e em que fossem observadas atividades elétricas atribuíveis à captura atencional. Desse modo, apesar de considerarmos que não observamos o efeito atencional nos experimentos $1 \mathrm{~B}, 2$ e 4 porque o estímulo precedente de fato não capturou a atenção nesses experimentos, fazer registros de eletrofisiologia ou neuroimagem nessas condições nos permitiria corroborar essa explicação.

Existe um amplo conjunto de trabalhos das últimas duas décadas na literatura, sobre o fenômeno da captura da atenção, discutindo diferentes situações experimentais em que essa captura parece não ocorrer. Essas discussões giram em torno de duas possibilidades diferentes para os mecanismos envolvidos na captura da atenção por um estímulo: a primeira possibilidade é que um estímulo saliente sempre captura a atenção, e a segunda possibilidade é que a captura da atenção por um estímulo é modulada e depende da relação entre as 
características desse estímulo e as configurações atencionais do sujeito. Essa segunda hipótese é conhecida na literatura como hipótese da captura contingente da atenção.

Alguns dos trabalhos de maior impacto defendendo que um estímulo saliente captura a atenção, sem que essa captura seja modulada por informações provenientes de regiões hierarquicamente superiores no processamento, são os estudos realizados por Theeuwes e colaboradores (THEEUWES 1991, 1992, 1993, 1994, 2010; THEEUWES; BURGER, 1998; SCHREIJ; OWENS; THEEUWES, 2008; VAN-DER-STIGCHEL et al., 2009; BELOPOLSKY; THEEUWES, 2010). De acordo com esse modelo, o primeiro estágio de processamento é direcionado pelo processamento anterógrado do estímulo, determinado unicamente pelas suas propriedades físicas, e o controle de regiões hierarquicamente superiores de processamento pode influenciar a seleção apenas quando esse processamento inicial está completo. O controle de regiões hierarquicamente superiores no processamento poderia limitar a seleção espacial apenas ajustando o tamanho da janela atencional. $\mathrm{O}$ tamanho da janela atencional teria um papel crucial na seleção visual e a captura atencional não ocorreria quando o tamanho da janela atencional fosse reduzido, com o estímulo estivesse fora da janela atencional.

Nesses trabalhos, um estímulo saliente, irrelevante para a tarefa, apresentado em uma tarefa de busca visual sempre provoca um efeito de lentificação na resposta ao alvo, interpretado como devido à captura da atenção pelo estímulo saliente. Nesse caso, o estímulo saliente ativaria mecanismos atencionais e, uma vez que a atenção precisaria ser reorientada do estímulo saliente irrelevante para o estímulo alvo para que a resposta fosse dada, a resposta ao alvo seria mais lenta do que na ausência de um estímulo saliente competidor. Assim, esses resultados foram interpretados como uma evidência de que um estímulo saliente, como os estímulos distraidores utilizados nessas tarefas, sempre captura a atenção, mesmo que não tenha relação nenhuma com os estímulos relevantes para a tarefa. Uma explicação alternativa para esses resultados, defendida por pesquisadores que consideram que a captura atencional é modulada e, portanto, não poderia ocorrer no caso de um estímulo que não tivesse nenhuma relevância para a tarefa, é que os efeitos observados nesse tipo de experimento se devem a custos de filtragem de estímulos competidores e não à captura da atenção por esses estímulos. De acordo com essa explicação, o efeito de lentificação do tempo de resposta na presença de um estímulo saliente irrelevante para a tarefa ocorreria pela demora em processar os estímulos numa situação de maior demanda sensorial. Não haveria mecanismos atencionais envolvidos nesse efeito. 
A necessidade de uma explicação adicional desse tipo para esses resultados vem do fato de que, para os defensores da captura contingente da atenção, a captura da atenção por um estímulo é modulada pela contigência entre esse estímulo e um estímulo alvo de interesse para o sujeito. Essa contingência seria estabelecida relação de semelhança física entre o estímulo que captura a atenção (estímulo distraidor, no caso de tarefas de busca visual, ou estímulo precedente, no caso de procedimentos derivados do procedimento de Posner). Assim, um estímulo capturaria a atenção quando tivesse uma característica física em comum com o estímulo de interesse para o sujeito, como, por exemplo, a mesma cor ou uma forma semelhante.

Essa hipótese foi desenvolvida a partir de uma série de experimentos, entre os quais se destacam na literatura os trabalhos de Folk e colaboradores (FOLK; REMINGTON; JOHNSTON, 1992; FOLK; REMINGTON; WRIGHT, 1994; FOLK; REMINGTON, 1999) em que ocorre o efeito atencional quando o estímulo precedente tem alguma característica física em comum com o estímulo alvo e não é observado o efeito atencional quando não existe nenhuma característica física em comum entre os dois estímulos.

Os pesquisadores que defendem que um estímulo saliente sempre captura a atenção, como Theeuwes e colaboradores, explicam esse conjunto particular de resultados com hipóteses adicionais, como a hipótese de que a atenção seria capturada em todas as condições por um estímulo saliente, mas seria rapidamente desengajada do local de aparecimento do estímulo precedente se este não tivesse nenhuma semelhança com o estímulo alvo.

Tanto no caso do modelo proposto por Theeuwes como no caso do modelo proposto por Folk, é necessário lançar mão de hipóteses adicionais para explicar um conjunto de resultados que não é adequadamente explicado pelo modelo geral do mecanismo de captura da atenção que está sendo defendido. Desse modo, essas duas explicações para os mecanismos de captura atencional, com suas hipóteses adicionais, não são tão parcimoniosas como uma única explicação que desse conta de todo esse conjunto de resultados. Além disso, a explicação de Theeuwes e colaboradores, de que a atenção seria capturada sempre por um estímulo mas seria rapidamente desengajada do local de aparecimento do estímulo precedente quando este não fosse semelhante ao estímulo alvo tem o problema adicional de ser difícil de ser falseada, conforme discutido anteriormente.

Se considerarmos que a aparente discrepância entre esses resultados pode ser devido à diferença entre as tarefas realizados pelo sujeito em cada experimento, concluímos que o ideal 
é dispormos de uma hipótese sobre os mecanismos de captura atencional que dê conta do conjunto de resultados de ambos os tipos de tarefa, sem a necessidade da elaboração de hipóteses adicionais para explicar resultados que sejam tratados como "exceções à regra."

Tendo em vista o conjunto de resultados apresentados nesse trabalho, nossos e encontrados na literatura, acreditamos ser pouco provável que um estímulo sempre capture a atenção. Parece-nos mais provável que a captura atencional seja modulada por uma contingência entre o estímulo apresentado e as características dos demais estímulos relevantes para a tarefa.

Supor, no entanto, que essa contingência é determinada apenas pela semelhança física entre os estímulos não permite que se expliquem parte dos resultados discutidos aqui. Em todos os nossos experimentos, as características físicas que determinam os estímulos precedente e alvo foram as mesmas. Ainda assim, o efeito da captura atencional foi observado quando havia demarcações ou linhas intensas na tela de fundo, mas não quando essa tela era vazia ou possuia linhas de baixa intensidade. Se existe algo modulando a captura da atenção pelo estímulo precedente nesse caso, não pode ser o grau de semelhança física entre o estímulo precedente e o estímulo alvo.

Além disso, nos resultados apresentados por Macea et al. (2006), o efeito atencional aparece quando o estímulo alvo é uma linha e não quando o estímulo alvo utilizado é uma cruz. Entretanto, o efeito atencional passa a aparecer também para a cruz quando o estímulo alvo negativo é um X, menos distinto da cruz. Esse conjunto de resultados também não pode ser explicado pela relação de semelhança entre o estímulo precedente e o estímulo alvo, uma vez que o estímulo precedente utilizado é o mesmo em todas as situações.

A necessidade de uma hipótese mais geral para explicar o mecanismo subjacente à captura atencional fica clara a partir das discrepâncias encontradas. Mais recentemente, Becker, Folk e Remington (2010) defendem uma hipótese que passa a considerar a relação entre as características do estímulo alvo e as características dos demais estímulos (relações de comparação, como se são mais claros ou escuros, maiores ou menores, mais ou menos coloridos). Eles mostraram que um estímulo menos parecido com o estímulo alvo, mas que apresenta a mesma propriedade relativa que distingue alvos de outros estímulos pode capturar a atenção com a mesma eficiência do que estímulos que são mais parecidos com o alvo. 
Nossa proposta é a utilização de uma hipótese mais abrangente da captura contingente da atenção, que considere que qualquer fator capaz de modificar a relação entre o processamento dos estímulos apresentados pode modular a captura da atenção. Esses fatores não precisariam se limitar a semelhanças nas características físicas dos estímulos. Podemos nos referir a essa hipótese como uma hipótese estendida da captura contingente da atenção.

De acordo com essa proposta, o fator crítico para que um estímulo capture a atenção é o grau de sobreposição entre as redes neuronais que representam esse estímulo e as redes neuronais que estejam ativadas no momento. No caso de tarefas como as apresentadas aqui, as redes neuronais ativadas durante a realização da tarefa dependem da representação do estímulo alvo que é mantida durante toda a tarefa. As redes neuronais ativadas podem ser afetadas, portanto, tanto pelas características do estímulo alvo como por quaisquer outros fatores que afetem a representação do estímulo alvo.

Assim, se a representação de estímulos irrelevantes para o desempenho da tarefa, como é o caso do estímulo precedente, for distinta o suficiente da representação do estímulo alvo, esses estímulos não capturam a atenção. Mas, por outro lado, se a representação do estímulo alvo for mais inespecífica, quaisquer estímulos que não se dinstinguam o suficiente dessa representação ativada poderão capturar a atenção.

Isso explicaria por que a adição de estimulos competidores em uma cena visual leva ao aparecimento do efeito atencional, o que não é explicado satisfatoriamente quando se considera a hipótese tradicional da captura contingente da atenção. No caso de estímulos com características físicas semelhantes àquelas do estímulo alvo a sobreposição é evidente, de modo que esses resultados são bem explicados utilizando esse modelo. Explica, também, porque estímulos salientes capturam a atenção em uma tarefa de busca visual, mesmo quando não compartilham uma característica física evidente em comum com o alvo: a representação do estímulo alvo estaria ativa, mas de um modo mais difuso, devido à inclusão de sinais relacionados com os estímulos competidores, como ocorre nos nossos experimentos 1B e 4, em que o estímulo precedente não é mais parecido com o alvo do que nas demais situações mas captura a atenção.

De fato, se voltarmos a refletir acerca de como experienciamos no nosso cotidiano a atividade do nosso sistema visual, selecionando a todo momento as informações disponíveis no ambiente, podemos verificar que a maneira como os estímulos são considerados internamente depende em grande parte da quantidade de estímulos presentes em uma cena 
visual, e que essa dependência pode alterar a capacidade de um estímulo capturar a nossa atenção. Imaginemos duas situações diferentes em que estamos em uma estação de metrô, onde devemos encontrar uma pessoa. No caso de uma situação em que a estação de metrô esteja vazia, não teremos dificuldade em encontrar a pessoa que procuramos e dificilmente outra pessoa chamará a nossa atenção se estivermos concentrados na tarefa de procurar pela pessoa que esperamos. Apenas uma pessoa muito parecida com a pessoa que esperamos poderia capturar a nossa atenção nessas condições. Por outro lado, no caso de uma situação em que a estação de metrô esteja lotada, ao realizarmos a tarefa de procurar a pessoa que estamos esperando nossa atenção é capturada por um grande número de outras pessoas que estejam circulando no local, muitas das quais não possuem uma semelhança física evidente com a pessoa que procuramos. Nessa segunda situação, podemos imaginar que nossa representação dos estímulos estaria mais difusa, devido à necessidade de processar uma maior quantidade de informação para realizar a mesma tarefa e, assim, uma maior diversidade de estímulos poderia capturar a nossa atenção. 


\section{CONCLUSÕES}

Os resultados do presente estudo demonstram que a ocorrência do efeito atencional nos testes de atenção encoberta de Posner depende de modo importante da presença de estímulos concorrentes com o estímulo alvo.

Eles sugerem que a captura da atenção por um estímulo é modulada de acordo com a configuração de estímulos apresentados em uma cena visual. A presença de estímulos competidores pode ser um fator que modula essa captura da atenção. Possivelmente, o grau de sobreposição entre as redes neuronais que representam o estímulo apresentado e as redes neuronais ativadas durante a realização da tarefa determinam se o estímulo apresentado ativa ou não mecanismos atencionais. 


\section{REFERÊNCIAS ${ }^{1}$}

AYABE, T.; ISHIZU, T.; KOJIMA, S.; URAKAWA, T.; NISHITANI, N.; KANEOKE, Y.; KAKIGI, R. Neural processes of attentional inhibition of return traced with magnetoencephalography. Neuroscience, v. 156, n. 3, p. 769-780, 2008.

BECKER, S. I.; FOLK, C. L.; REMINGTON, R. W. The role of relational information in contingent capture. Journal of Experimental Psychology: Human Perception and Performance, v. 36, n. 6, p. 1460-1476, 2010.

BELOPOLSKY, A. V.; THEEUWES, J. No capture outside the attentional window. Vision Research, v.50, n. 23, p. 2543-2550, 2010.

BERLUCCHI, G. Inhibition of return: A phenomenon in search of a mechanism and a better name. Cognitive Neuropsychology, v. 23, n. 7, p. 1065-1074, 2006.

BIAND, K. A.; KLEIN, R. M. Is Posner's "beam" de same as Treisman's "glue"?: On the relation between visual orienting and feature integration theory. Journal of Experimental Psychology: Human Perception and Performance, v. 13, n. 2, p. 228-241, 1987.

CHEN, P.; MORDKOFF, J. T. Contingent capture at very short SOA: Evidence against rapid disengagement. Visual Cognition, v. 15, n. 6, p. 637-645, 2007.

CHICA, A. B.; LUPIÁÑEZ, J.; BARTOLOMEO, P. Dissociating inhibition of return from endogenous orienting of spatial attention: EvidenCe from detection and discrimination tasks. Cognitive Neuropsychology, v. 23, n. 7, p. 1015-1034, 2006.

EIMER, M.; KISS, M. Involuntary attentional capture is determined by task set: Evidence from event-related brain potentials. Journal of Cognitive Neuroscience, v. 20, n. 8, p. 14231433, 2008.

EIMER, M.; KISS, M. Top-down search strategies determine attentional capture in visual search: Behavioral and electrophysiological evidence. Attention, Perception and Psychophysics, v. 72, n. 4, p. 951-962, 2010.

\footnotetext{
${ }^{1}$ De acordo com: ASSOCIAÇÃO BRASILEIRA DE NORMAS TÉCNICAS. NBR 6023: Informação e documentação: referências: elaboração. Rio de Janeiro, 2002.
} 
EIMER, M.; KISS, M.; PRESS, C.; SAUTER, D. The roles of feature-specific task set and bottom-up salience in attentional capture: An ERP study. Journal of Experimental Psychology: Human Perception and Performance, v. 35, n. 5, p. 1316-1328, 2009.

FECTEAU, J. H.; MUNOZ, D. P. Salience, relevance, and firing: a priority map for target selection. Trends in Cognitive Sciences, v. 10, n. 8, p. 382-390, 2006.

FOLK, C. L.; REMINGTON, R. W.; JOHNSTON, J. Involuntary covert orienting is contingent on attentional control settings. Journal of Experimental Psychology: Human Perception and Performance, v. 18, n. 4, p. 1030-1044, 1992.

FOLK, C. L.; REMINGTON, R. W.; WIRGHT, J. H. The structure of attentional control: contingent attentional capture by apparent motion, abrupt onset, and color. Journal of Experimental Psychology: Human Perception and Performance, v. 20, n. 2, p. 317-329, 1994.

FOLK, C. L.; REMINGTON, R. W. Selectivity in distraction by irrelevant featural singletons: Evidence for two forms of attentional capture. Journal of Experimental Psychology: Human Perception and Performance, v. 24, p. 847-858, 1998.

FOLK, C. L.; REMINGTON, R. W. Can new objetcs override attentional control settings? Perception and Psychophysics, v. 61, n. 4, p. 727-739, 1999.

FOLK, C. L.; REMINGTON, R. W. Top-down modulation of preattentive processing: Testing the recovery account of contingent capture. Visual Cognition, v. 14, n. 4, p. 445-465, 2006.

GIBSON, B. S.; AMELIO, J. Inhibition of return and attentional control settings. Perception Psychophysics, v. 62, n. 3, p. 496-504, 2000.

GRECHI, G. Existe assimetria interlateral na capacidade de reorientação da atenção visuoespacial automática? 2006. 135 p. Dissertação (Mestrado em Fisiologia Humana) Instituto de Ciências Biomédicas, Universidade de São Paulo, São Paulo, 2006.

HATFIELD, G. Attention in early scientific psychology. In: WRIGHT, R. D. (Ed.). Visual attention. New York: Oxford University Press, 1998. p. 3-25

KEYSERS, C.; PERRET, D. I. Visual masking and RSVP reveal neural competition. Trends in Cognitive Sciences, v. 6, n. 3, p. 120-125, 2002. 
KISS, M.; JOLICOEUR, P.; DELL'ACQUA, R.; EIMER, M. Attentional capture by visual singletons is mediated by top-down task set: New evidentce from de N2pc component. Psychophysiology, v. 45, n. 6, p. 1013-1024, 2008.

KISS, M.; VAN-VELZEN, J.; EIMER, M. The N2pc component and its links to attention shifts and spatially selective visual processing. Psychophysiology, v. 45, n. 2, p. 240-249, 2008 .

KLEIN, R. M. Inhibition of Return. Trends in Cognitive Sciences, v. 4. n. 4, p. 139-146, 2000.

LAMY, D. Reevaluating the disengagement hypothesis. Acta Psychologica, v. 134, n. 2, p. 127-129, 2010.

LAMY, D.; EGETH, H. E. Attentional capture in singleton-detection and feature-search modes. Journal of Experimental Psychology: Human Perception and Performance, v. 29, p. 1003-1020, 2003.

LAMY, D.; LEBER, A.; EGETH, H. E. Effects of task relevance and stimulus-driven salience in feature-search mode. Journal of Experimental Psychology: Human Perception and Performance, v. 30, n. 6, p. 1019-1031, 2004.

LEBLANC, E.; PRIME, D. J.; JOLICOEUR, P. Tracking the location of visuospatial attention in a contingent capture paradigm. Journal of Cognitive Neuroscience, v. 20, n. 4, p. 657-671, 2008.

LEPSIEN, J.; POLLMANN, S. Covert reorienting and inhibition of return: an event-related fMRI study. Journal of Cognitive Neuroscience, v. 14, n. 2, p. 127-144, 2002.

LU, Z. L.; DOSHER, B. A. External noise distinguishes attentional mechanisms. Vision Research, v. 38, p. 1183-1198, 1998.

LU, Z. L.; DOSHER, B. A. Spatial attention: Different mechanisms for central and peripheral precues? Journal of Experimental Psychology: Human Perception and Performance, v. 26, p. 1534-1548, 2000.

LUPIÁÑEZ, J.; MILLIKEN, B.; SOLANO, C.; WEAVER, B.; TIPPER, S. P. On the strategic modulation of the time course of facilitation and inhibition of return. The Quarterly Journal of Experimental Psychology, v. 54A, n. 3, p. 753-773, 2001. 
LUPIÁÑEZ, J.; DECAIX, C.; SIÉROFF, E.; CHOKRON， S.; MILLIKEN, B.; BARTOLOMEO, P. Independent effects of endogenous and exogenous spatial cueing: inhibition of return at endogenously attended target locations. Experimental Brain Research, v. 159, n. 4, p. 447-457, 2004.

MACEA, D. D.; ABBUD, G. A. C.; LOPES-DE-OLIVEIRA, M. I.; FUGA, N. B.; RIBEIRODO-VALLE, L. E. Control of attention by a peripheral visual cue depends on whether the target is difficult to discriminate. Brazilian Journal of Medical and Biological Research, v. 39, p. 957-968, 2006.

MACKNIC, S. L.; LIVINGSTONE, M. S. Neuronal correlates of visibility and invisibility in the primate visual system. Nature Neuroscience, v. 1, n. 2, p. 144-149, 1998.

MÜLLER, H. J.; GEYER, T.; ZEHETLEITNER, M.; KRUMMENACHER, J. Attentional capture by salient color singleton distractors is modulated by top-down dimensional set. Journal of Experimental Psychology: Human Perception and Performance, v. 35, n. 1, p. 1$16,2009$.

PETROV, Y.; MCKEE, S. P. The time course of contrast masking reveals two distinct mechanisms of human surround supression. Journal of Vision, v. 9, n. 1, p. 1-11, 2009.

POORESMAEILI, A.; HERRERO, J. L.; SELF, M. W.; ROELFSEMA, R.; THIELE, A. Supressive lateral interactions at parafoveal representations in primary visual cortex. The Journal of Neuroscience, v. 30, n. 38, p. 12745-12758, 2010.

POSNER, M. I. Orienting of attention. Quarterly Journal of Experimental Psychology, v. 32, p. 3-25, 1980.

POSNER, M. I.; COHEN, Y. A. Components of visual orienting. In: BOUMA, H.; BOUWHUIS, D. G. (Ed.). Attention and Performance X. Hillsdale, NJ: Lawrence Erlbaum and Associates, 1984. p. 531-554.

POSNER, M. I.; SNYDER, C.; DAVIDSON, B. Attention and the detection of signals. Journal of Experimental Psychology: General, v. 109, n. 2, p. 160-174, 1980.

SCHREIJ, D.; OWENS, C.; THEEUWES, J. Abrupt onsets capture attention independent of top-down control settings. Perception and Psychophysics, v. 70, n. 2, p. 208-218, 2008. 
SCHREIJ, D.; THEEUWES, J.; OLIVERS, C. N. Irrelevant onsets cause inhibition of return regardless of attentional set. Attention, Perception and Psychophysics, v. 72, n. 7, p. 1725$1729,2010$.

SNYDER, J. J.; KINGSTONE, A.; SCHMIDT, W. C. Attentional momentum does not underlie the inhibition of return effect. Journal of Experimental Psychology: Human Perception and Performance, v. 27, n. 6, p. 1420-1432, 2001.

SNYDER, J. J.; SCHMIDT, W. C.; KINGSTONE. A. There's Little Return for Attentional Momentum. Journal of Experimental Psychology: Human Perception and Performance, v. 35, n. 6, p. 1726-1737, 2009.

STOKES, M.; THOMPSON, R.; NOBRE, A. C.; DUNCAN, J. Shape-specific preparatory activity mediates attention to targets in human visual cortex. PNAS, v. 106, n. 46, p. 1956919574, 2009.

THEEUWES, J. Cross-dimensional perceptual selectivity. Perception and Psychophysics, v. 50, n. 2, p. 184-193, 1991.

THEEUWES, J. Perceptual selectivity for color and form. Perception and Psychophysics, v. 51, n. 6, p. 599-606, 1992.

THEEUWES, J. Visual selective attention: a theoretical analysis. Acta Psychologica, v. 83, n. 2, p. 93-154, 1993.

THEEUWES, J. Endogenous and exogenous control of visual selection. Perception, v. 23, n. 4, p. 429-440, 1994.

THEEUWES, J. Stimulus-driven capture and attentional set: selective search for color and visual abrupt onsets. Journal of Experimental Psychology: Human Perception and Performance, v. 20, n. 4, p. 799-806, 1994.

THEEUWES, J.; BURGER, R. Attentional control during visual search: the effect of irrelevant singletons. Journal of Experimental Psychology: Human Perception and Performance, v. 24, n. 5, p. 1342-1353, 1998.

THEEUWES, J.; GODIJN, R. Irrelevant singletons capture attention: Evidence from inhibition of return. Perception and Psychophysics, v. 64, n. 5, p. 764-770, 2002. 
THEEUWES, J. Top-down and bottom-up control of visual attention. Acta Psychologica, v. 135, n. 2, p. 77-99, 2010.

VAN-DER-STIGCHEL, S.; BELOPOLSKY, A. V.; PETERS, J. C.; WIKNEN, J. G.; MEETER, M.; THEEUWES, J. The limits of top-down control of visual attention. Acta Psychologica, v. 132, n. 3, p. 201-212, 2009.

WOODMAN, G. F.; ARITA, J. T.; LUCK, S. J. A cueing study of the N2pc component: An index of attentional deployment to objetcts rather than spatial locations. Brain Research, $\mathrm{v}$. 1297, p. 101-111, 2009.

WRIGHT, R. D.; WARD, L. M. Orienting of Attention. New York: Oxford University Press; 2008. 
ANEXOS 


\section{ANEXO A - Termo de Anuência}

Você está sendo convidado a participar como voluntário de um estudo psicofisiológico. Este estudo está sendo conduzido por Fernanda A. Sais, sob orientação e supervisão do Prof. Dr. Luiz Eduardo Ribeiro do Valle. Ele será realizado nas dependências do Departamento de Fisiologia e Biofísica do ICB da USP.

Você realizará 2 sessões de testes, a primeira durando cerca de 20 min e a segunda cerca de 30 min. Ambas as sessões serão realizadas em uma sala com iluminação reduzida, algum isolamento acústico e ventilação adequada. Durante as sessões você permanecerá sentado em frente a uma mesa e responderá a estímulos visuais simples, apresentados em um monitor de vídeo, pressionando uma tecla com o dedo indicador de sua mão esquerda ou de sua mão direita. O experimento não oferece qualquer risco potencial para sua saúde.

Sua participação no estudo é totalmente voluntária. Você é livre para abandoná-lo no momento em que quiser.

Eu li a proposta acima e entendi os procedimentos. Eu me disponho a participar como voluntário neste estudo.

Nome:

Assinatura:

Data:

(1)




\section{ANEXO B - Questionário de Edinburgh (adaptado)}

Nome

Idade anos

Você já teve alguma tendência a ser canhoto?

Existe algum canhoto na sua família?

Indicar a preferência manual nas atividades abaixo. Assinale ++ na coluna apropriada quando a preferência for tão forte que você nunca use a outra mão. Assinale ++ e + nas colunas apropriadas quando preferir usar uma das mãos mas de vez em quando também usar a outra. Assinale ++ nas duas colunas quando usar indistintamente qualquer uma das mãos.

\begin{tabular}{|l|l|l|}
\hline Atividades & Direita & Esquerda \\
\hline Escrever & & \\
\hline Desenhar & & \\
\hline Jogar uma pedra & & \\
\hline Usar uma tesoura & & \\
\hline Usar um pente & & \\
\hline Usar uma escova de dentes & & \\
\hline Usar uma faca (sem o uso do garfo) & & \\
\hline Usar uma colher & & \\
\hline Usar um martelo & & \\
\hline Usar uma chave de fendas & & \\
\hline Usar uma raquete de ping-pong & & \\
\hline Usar uma faca (com o garfo) & & \\
\hline Usar uma vassoura (mão superior) & & \\
\hline Usar um rodo (mão superior) & & \\
\hline Acender um fósforo & & \\
\hline Abrir um vidro com tampa (mão que segura a tampa) & & \\
\hline Distribuir cartas & & \\
\hline Enfiar a linha na agulha (mão que segura a linha) & & \\
\hline Total & & \\
\hline
\end{tabular}

Quociente de Lateralidade $[(\mathrm{D}-\mathrm{E}) /(\mathrm{D}+\mathrm{E})]$

Dominância Pedal (chutar uma bola)

Dominância Visual Apontando

Acuidade Visual

$\mathrm{OE}$

Fotografando

Visão de Cores

Duração do Sono

Horário Preferido para Acordar

Data da Última Menstruação

Regularidade do Ciclo

Medicamentos em Uso

Hábito de Brincar com Jogos Eletrônicos

Observações 
ANEXO C - Tabela para teste de acuidade visual

\section{Tabela de leitura para perto}

$0,37 m$

45858

$0,50 \mathrm{~m}$

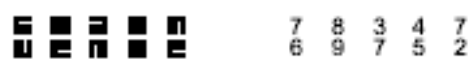

$0,67 m$

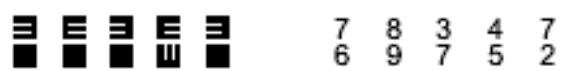

$0,75 \mathrm{~m}$

티 비 트 틀 $\quad \begin{array}{llll}8 & 5 & 4 & 9 \\ 3 & 2 & 7 & 6\end{array}$

J4

$1,00 \mathrm{~m}$

E 프 트 $\quad \begin{array}{llll}6 & 7 & 2 & 6\end{array}$

J5

$1,25 \mathrm{~m}$

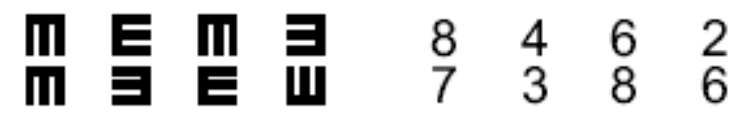

J6 


\section{ANEXO D - Teste de Ishihara}

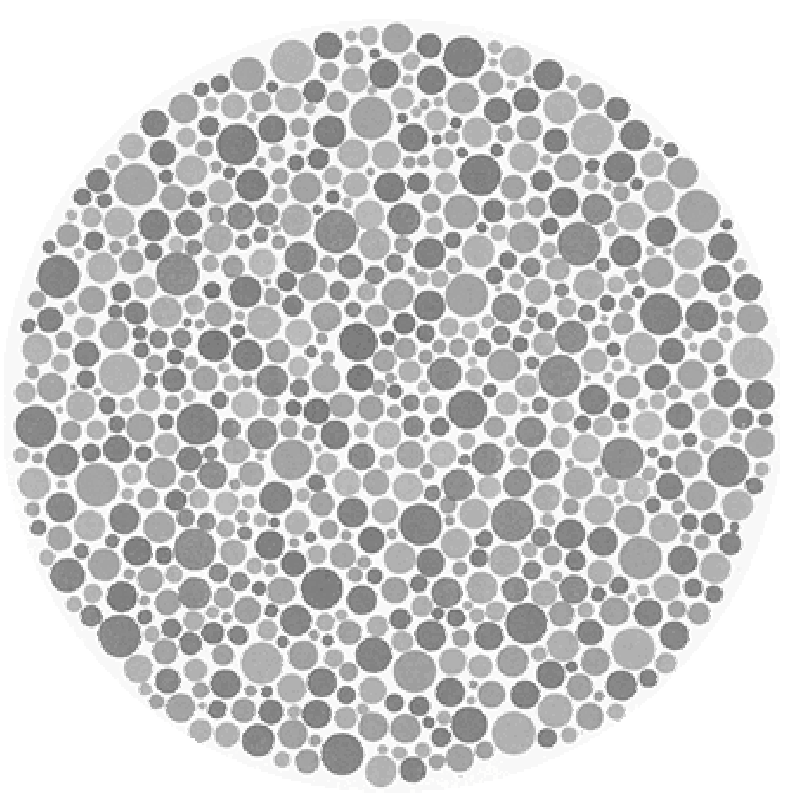




\section{ANEXO E - Tabelas de dados do Experimento 1}

Tempos de reação (em ms) nas assincronias de 100, 400 e 800 ms no Experimento 1A, com demarcações na tela.

\begin{tabular}{c|cccccc} 
AlE & \multicolumn{2}{|c}{$\mathbf{1 0 0}$} & \multicolumn{2}{c}{$\mathbf{4 0 0}$} & \multicolumn{2}{c}{$\mathbf{8 0 0}$} \\
\hline E1-E2 & $\mathbf{M}$ & $\mathbf{O}$ & $\mathbf{M}$ & $\mathbf{O}$ & $\mathbf{M}$ & $\mathbf{O}$ \\
$\mathbf{2}$ & 356 & 381 & 355 & 350 & 342 & 359 \\
$\mathbf{3}$ & 303 & 329 & 302 & 295 & 293 & 293 \\
$\mathbf{6}$ & 316 & 337 & 303 & 313 & 304 & 293 \\
$\mathbf{7}$ & 338 & 377 & 337 & 355 & 337 & 341 \\
$\mathbf{8}$ & 317 & 322 & 309 & 311 & 302 & 297 \\
$\mathbf{1 3}$ & 392 & 401 & 372 & 373 & 367 & 362 \\
$\mathbf{1 4}$ & 375 & 400 & 383 & 388 & 396 & 371 \\
$\mathbf{1 5}$ & 326 & 341 & 315 & 316 & 323 & 316 \\
$\mathbf{1 7}$ & 367 & 377 & 360 & 366 & 359 & 338 \\
$\mathbf{1 9}$ & 311 & 343 & 312 & 315 & 292 & 278 \\
$\mathbf{2 0}$ & 303 & 322 & 292 & 298 & 287 & 281 \\
$\mathbf{2 1}$ & 310 & 321 & 289 & 301 & 286 & 276 \\
Média & $\mathbf{3 3 5}$ & $\mathbf{3 5 4}$ & $\mathbf{3 2 7}$ & $\mathbf{3 3 2}$ & $\mathbf{3 2 4}$ & $\mathbf{3 1 7}$ \\
E.p.m. & $\mathbf{9}$ & $\mathbf{9}$ & $\mathbf{9}$ & $\mathbf{9}$ & $\mathbf{1 0}$ & $\mathbf{1 0}$
\end{tabular}

Efeito do estímulo precedente nas assincronias de 100, 400 e 800 ms no Experimento 1A, com demarcações na tela (tempo de reação na condição oposta - tempo de reação na condição mesma).

\begin{tabular}{r|ccc}
\multicolumn{1}{l|}{ AIE } & $\mathbf{1 0 0}$ & $\mathbf{4 0 0}$ & $\mathbf{8 0 0}$ \\
\hline E1-E2 & & & \\
$\mathbf{2}$ & 25 & -5 & 17 \\
$\mathbf{3}$ & 26 & -7 & 0 \\
$\mathbf{6}$ & 21 & 10 & -11 \\
$\mathbf{7}$ & 39 & 18 & 4 \\
$\mathbf{8}$ & 5 & 2 & -5 \\
$\mathbf{1 3}$ & 9 & 1 & -5 \\
$\mathbf{1 4}$ & 25 & 5 & -25 \\
$\mathbf{1 5}$ & 15 & 1 & -7 \\
$\mathbf{1 7}$ & 10 & 6 & -21 \\
$\mathbf{1 9}$ & 32 & 3 & -14 \\
$\mathbf{2 0}$ & 19 & 6 & -6 \\
$\mathbf{2 1}$ & 11 & 12 & -10 \\
Média & $\mathbf{2 0}$ & $\mathbf{4}$ & $-\mathbf{7}$ \\
E.p.m. & $\mathbf{3}$ & $\mathbf{2}$ & $\mathbf{3}$
\end{tabular}


Tempos de reação (em ms) nas assincronias de 100, 400 e 800 ms no Experimento 1B, sem demarcações na tela.

\begin{tabular}{c|cccccc} 
AIE & \multicolumn{2}{|c}{$\mathbf{1 0 0}$} & \multicolumn{2}{c}{$\mathbf{4 0 0}$} & \multicolumn{2}{c}{$\mathbf{8 0 0}$} \\
\hline E1-E2 & $\mathbf{M}$ & $\mathbf{O}$ & $\mathbf{M}$ & $\mathbf{O}$ & $\mathbf{M}$ & $\mathbf{0}$ \\
$\mathbf{2}$ & 416 & 415 & 376 & 357 & 359 & 338 \\
$\mathbf{3}$ & 363 & 393 & 364 & 370 & 337 & 328 \\
$\mathbf{4}$ & 299 & 276 & 257 & 229 & 248 & 245 \\
$\mathbf{5}$ & 296 & 284 & 295 & 251 & 279 & 247 \\
$\mathbf{6}$ & 376 & 390 & 317 & 318 & 320 & 309 \\
$\mathbf{9}$ & 291 & 302 & 292 & 271 & 280 & 275 \\
$\mathbf{1 0}$ & 384 & 392 & 333 & 353 & 333 & 329 \\
$\mathbf{1 1}$ & 296 & 285 & 289 & 260 & 285 & 269 \\
$\mathbf{1 2}$ & 338 & 349 & 298 & 286 & 295 & 271 \\
$\mathbf{1 3}$ & 372 & 329 & 310 & 270 & 289 & 269 \\
$\mathbf{1 4}$ & 322 & 343 & 300 & 301 & 300 & 286 \\
$\mathbf{2 1}$ & 313 & 301 & 287 & 275 & 289 & 275 \\
Média & $\mathbf{3 3 9}$ & $\mathbf{3 3 8}$ & $\mathbf{3 1 0}$ & $\mathbf{2 9 5}$ & $\mathbf{3 0 1}$ & $\mathbf{2 8 7}$ \\
E.p.m. & $\mathbf{1 2}$ & $\mathbf{1 4}$ & $\mathbf{1 0}$ & $\mathbf{1 3}$ & $\mathbf{9}$ & $\mathbf{9}$
\end{tabular}

Efeito do estímulo precedente nas assincronias de 100, 400 e $800 \mathrm{~ms}$ no Experimento 1B, sem demarcações na tela (tempo de reação na condição oposta - tempo de reação na condição mesma).

\begin{tabular}{c|ccc} 
AIE & $\mathbf{1 0 0}$ & $\mathbf{4 0 0}$ & $\mathbf{8 0 0}$ \\
\hline E1-E2 & & & \\
$\mathbf{2}$ & -1 & -19 & -21 \\
$\mathbf{3}$ & 30 & 6 & -9 \\
$\mathbf{4}$ & -23 & -28 & -3 \\
$\mathbf{5}$ & -12 & -44 & -32 \\
$\mathbf{6}$ & 14 & 1 & -11 \\
$\mathbf{9}$ & 11 & -21 & -5 \\
$\mathbf{1 0}$ & 8 & 20 & -4 \\
$\mathbf{1 1}$ & -11 & -29 & -16 \\
$\mathbf{1 2}$ & 11 & -12 & -24 \\
$\mathbf{1 3}$ & -43 & -40 & -20 \\
$\mathbf{1 4}$ & 21 & 1 & -14 \\
$\mathbf{2 1}$ & -12 & -12 & -14 \\
Média & $\mathbf{- 1}$ & $\mathbf{- 1 5}$ & $\mathbf{- 1 4}$ \\
E.p.m. & $\mathbf{6}$ & $\mathbf{6}$ & $\mathbf{3}$
\end{tabular}




\section{ANEXO F - Tabelas de dados do Experimento 2}

Tempos de reação (em ms) nas assincronias de 50, 100, 150, 200 e 250 ms no Experimento 2, com o fundo da tela vazio.

\begin{tabular}{c|cccccccccc} 
AIE & \multicolumn{3}{|c}{$\mathbf{5 0}$} & \multicolumn{1}{c}{$\mathbf{1 0 0}$} & \multicolumn{1}{c}{$\mathbf{1 5 0}$} & \multicolumn{2}{c}{$\mathbf{2 0 0}$} & \multicolumn{2}{c}{$\mathbf{2 5 0}$} \\
\hline E1-E2 & $\mathbf{M}$ & $\mathbf{O}$ & $\mathbf{M}$ & $\mathbf{O}$ & $\mathbf{M}$ & $\mathbf{O}$ & $\mathbf{M}$ & $\mathbf{O}$ & $\mathbf{M}$ & $\mathbf{0}$ \\
$\mathbf{4}$ & 363 & 343 & 331 & 318 & 318 & 299 & 313 & 284 & 301 & 290 \\
$\mathbf{9}$ & 410 & 410 & 389 & 399 & 373 & 392 & 364 & 379 & 363 & 377 \\
$\mathbf{1 1}$ & 356 & 339 & 317 & 340 & 294 & 320 & 297 & 320 & 274 & 307 \\
$\mathbf{1 2}$ & 387 & 345 & 327 & 335 & 312 & 325 & 306 & 288 & 315 & 287 \\
$\mathbf{1 5}$ & 342 & 364 & 315 & 331 & 307 & 312 & 296 & 303 & 302 & 287 \\
$\mathbf{1 6}$ & 387 & 379 & 341 & 326 & 328 & 327 & 297 & 327 & 287 & 307 \\
$\mathbf{2 4}$ & 353 & 372 & 340 & 372 & 327 & 352 & 303 & 361 & 289 & 366 \\
$\mathbf{2 5}$ & 390 & 368 & 329 & 320 & 316 & 322 & 293 & 300 & 282 & 289 \\
$\mathbf{2 7}$ & 353 & 399 & 342 & 356 & 315 & 327 & 295 & 309 & 273 & 309 \\
$\mathbf{2 8}$ & 339 & 351 & 323 & 328 & 312 & 293 & 307 & 297 & 298 & 295 \\
$\mathbf{2 9}$ & 343 & 316 & 339 & 281 & 290 & 252 & 288 & 257 & 293 & 261 \\
$\mathbf{3 0}$ & 318 & 323 & 281 & 290 & 259 & 277 & 277 & 273 & 274 & 263 \\
Média & $\mathbf{3 6 2}$ & $\mathbf{3 5 9}$ & $\mathbf{3 3 1}$ & $\mathbf{3 3 3}$ & $\mathbf{3 1 3}$ & $\mathbf{3 1 6}$ & $\mathbf{3 0 3}$ & $\mathbf{3 0 8}$ & $\mathbf{2 9 6}$ & $\mathbf{3 0 3}$ \\
E.p.m. & $\mathbf{8}$ & $\mathbf{8}$ & $\mathbf{7}$ & $\mathbf{9}$ & $\mathbf{8}$ & $\mathbf{1 0}$ & $\mathbf{6}$ & $\mathbf{1 0}$ & $\mathbf{7}$ & $\mathbf{1 0}$
\end{tabular}

Efeito do estímulo precedente nas assincronias de 50, 100, 150, 200 e $250 \mathrm{~ms}$ no Experimento 2, com o fundo da tela vazio (tempo de reação na condição oposta - tempo de reação na condição mesma).

\begin{tabular}{c|ccccc} 
AIE & $\mathbf{5 0}$ & $\mathbf{1 0 0}$ & $\mathbf{1 5 0}$ & $\mathbf{2 0 0}$ & $\mathbf{2 5 0}$ \\
\hline $\mathbf{4}$ & -20 & -13 & -19 & -29 & -11 \\
$\mathbf{9}$ & 0 & 9 & 19 & 15 & 14 \\
$\mathbf{1 1}$ & -17 & 22 & 27 & 23 & 33 \\
$\mathbf{1 2}$ & -42 & 8 & 14 & -18 & -28 \\
$\mathbf{1 5}$ & 22 & 16 & 4 & 7 & -16 \\
$\mathbf{1 6}$ & -8 & -15 & -2 & 30 & 20 \\
$\mathbf{2 4}$ & 19 & 32 & 25 & 58 & 77 \\
$\mathbf{2 5}$ & -22 & -9 & 5 & 7 & 6 \\
$\mathbf{2 7}$ & 46 & 14 & 12 & 14 & 36 \\
$\mathbf{2 8}$ & 12 & 6 & -19 & -10 & -3 \\
$\mathbf{2 9}$ & -27 & -59 & -38 & -31 & -32 \\
$\mathbf{3 0}$ & 5 & 9 & 18 & -5 & -11 \\
Média & $-\mathbf{3}$ & $\mathbf{2}$ & $\mathbf{4}$ & $\mathbf{5}$ & $\mathbf{7}$ \\
E.p.m. & $\mathbf{7}$ & $\mathbf{7}$ & $\mathbf{6}$ & $\mathbf{7}$ & $\mathbf{9}$
\end{tabular}




\section{ANEXO G - Tabelas de dados do Experimento 3}

Tempos de reação (em ms) nas assincronias de 50, 100, 150, 200 e 250 ms no Experimento 3, com linhas verticais e horizontais de alta intensidade distribuídas no fundo da tela.

\begin{tabular}{c|cccccccccc} 
AIE & \multicolumn{3}{|c}{$\mathbf{5 0}$} & \multicolumn{1}{c}{$\mathbf{1 0 0}$} & \multicolumn{2}{c}{$\mathbf{1 5 0}$} & \multicolumn{2}{c}{$\mathbf{2 0 0}$} & \multicolumn{2}{c}{$\mathbf{2 5 0}$} \\
\hline E1-E2 & $\mathbf{M}$ & $\mathbf{O}$ & $\mathbf{M}$ & $\mathbf{O}$ & $\mathbf{M}$ & $\mathbf{O}$ & $\mathbf{M}$ & $\mathbf{O}$ & $\mathbf{M}$ & $\mathbf{O}$ \\
$\mathbf{1 4}$ & 341 & 371 & 325 & 348 & 340 & 345 & 307 & 318 & 305 & 293 \\
$\mathbf{1 5}$ & 390 & 406 & 342 & 369 & 365 & 383 & 354 & 373 & 342 & 385 \\
$\mathbf{1 6}$ & 418 & 437 & 368 & 410 & 338 & 377 & 318 & 361 & 317 & 354 \\
$\mathbf{1 7}$ & 464 & 463 & 418 & 424 & 398 & 432 & 361 & 380 & 354 & 401 \\
$\mathbf{1 8}$ & 358 & 340 & 333 & 321 & 311 & 309 & 319 & 300 & 306 & 334 \\
$\mathbf{1 9}$ & 384 & 392 & 340 & 360 & 342 & 348 & 294 & 349 & 324 & 330 \\
$\mathbf{2 1}$ & 398 & 402 & 351 & 376 & 334 & 363 & 297 & 334 & 320 & 307 \\
$\mathbf{2 3}$ & 390 & 376 & 348 & 344 & 326 & 338 & 313 & 320 & 310 & 324 \\
$\mathbf{2 4}$ & 375 & 426 & 331 & 380 & 297 & 355 & 271 & 352 & 263 & 365 \\
$\mathbf{2 5}$ & 372 & 418 & 369 & 384 & 342 & 353 & 334 & 338 & 334 & 334 \\
$\mathbf{2 9}$ & 316 & 294 & 293 & 278 & 293 & 264 & 275 & 260 & 264 & 253 \\
$\mathbf{3 0}$ & 402 & 393 & 369 & 356 & 333 & 349 & 319 & 329 & 317 & 324 \\
Média & $\mathbf{3 8 4}$ & $\mathbf{3 9 3}$ & $\mathbf{3 4 9}$ & $\mathbf{3 6 2}$ & $\mathbf{3 3 5}$ & $\mathbf{3 5 1}$ & $\mathbf{3 1 4}$ & $\mathbf{3 3 5}$ & $\mathbf{3 1 3}$ & $\mathbf{3 3 4}$ \\
E.p.m. & $\mathbf{1 1}$ & $\mathbf{1 3}$ & $\mathbf{9}$ & $\mathbf{1 1}$ & $\mathbf{8}$ & $\mathbf{1 2}$ & $\mathbf{8}$ & $\mathbf{1 0}$ & $\mathbf{8}$ & $\mathbf{1 2}$
\end{tabular}

Efeito do estímulo precedente nas assincronias de 50, 100, 150, 200 e $250 \mathrm{~ms}$ no Experimento 3, com linhas horizontais e verticais de alta intensidade distribuídas no fundo da tela (tempo de reação na condição oposta - tempo de reação na condição mesma).

\begin{tabular}{c|ccccc} 
AIE & $\mathbf{5 0}$ & $\mathbf{1 0 0}$ & $\mathbf{1 5 0}$ & $\mathbf{2 0 0}$ & $\mathbf{2 5 0}$ \\
\hline E1-E2 & & & & & \\
$\mathbf{1 4}$ & 30 & 23 & 5 & 11 & -12 \\
$\mathbf{1 5}$ & 16 & 27 & 18 & 19 & 43 \\
$\mathbf{1 6}$ & 19 & 42 & 39 & 43 & 37 \\
$\mathbf{1 7}$ & -1 & 6 & 34 & 19 & 47 \\
$\mathbf{1 8}$ & -18 & -12 & -2 & -19 & 28 \\
$\mathbf{1 9}$ & 8 & 20 & 6 & 55 & 6 \\
$\mathbf{2 1}$ & 4 & 25 & 29 & 37 & -13 \\
$\mathbf{2 3}$ & -14 & -4 & 12 & 7 & 14 \\
$\mathbf{2 4}$ & 51 & 49 & 58 & 81 & 102 \\
$\mathbf{2 5}$ & 46 & 15 & 11 & 4 & 0 \\
$\mathbf{2 9}$ & -22 & -16 & -29 & -15 & -11 \\
$\mathbf{3 0}$ & -9 & -13 & 16 & 10 & 7 \\
Média & $\mathbf{9}$ & $\mathbf{1 4}$ & $\mathbf{1 6}$ & $\mathbf{2 1}$ & $\mathbf{2 1}$ \\
E.p.m. & $\mathbf{7}$ & $\mathbf{6}$ & $\mathbf{6}$ & $\mathbf{8}$ & $\mathbf{1 0}$
\end{tabular}




\section{ANEXO H - Tabelas de dados do Experimento 4}

Tempos de reação (em ms) nas assincronias de 50, 100, 150, 200 e $250 \mathrm{~ms}$ no Experimento 4, com linhas verticais e horizontais de baixa intensidade distribuídas no fundo da tela.

\begin{tabular}{c|cccccccccc} 
AIE & \multicolumn{3}{|c}{$\mathbf{5 0}$} & \multicolumn{1}{c}{$\mathbf{1 0 0}$} & \multicolumn{2}{c}{$\mathbf{1 5 0}$} & \multicolumn{2}{c}{$\mathbf{2 0 0}$} & \multicolumn{2}{c}{$\mathbf{2 5 0}$} \\
\hline E1-E2 & $\mathrm{M}$ & $\mathrm{O}$ & $\mathrm{M}$ & $\mathrm{O}$ & $\mathrm{M}$ & $\mathrm{O}$ & $\mathrm{M}$ & $\mathrm{O}$ & $\mathrm{M}$ & $\mathrm{O}$ \\
$\mathbf{1}$ & 342 & 319 & 297 & 305 & 271 & 286 & 274 & 281 & 277 & 275 \\
$\mathbf{4}$ & 339 & 332 & 326 & 338 & 285 & 309 & 273 & 301 & 287 & 263 \\
$\mathbf{5}$ & 349 & 363 & 313 & 331 & 317 & 328 & 294 & 304 & 284 & 309 \\
$\mathbf{6}$ & 334 & 335 & 301 & 304 & 293 & 281 & 290 & 269 & 273 & 269 \\
$\mathbf{7}$ & 357 & 382 & 307 & 368 & 319 & 335 & 290 & 318 & 297 & 326 \\
$\mathbf{1 3}$ & 338 & 363 & 346 & 340 & 307 & 305 & 287 & 296 & 288 & 285 \\
$\mathbf{1 5}$ & 400 & 408 & 372 & 370 & 372 & 354 & 368 & 352 & 300 & 344 \\
$\mathbf{1 6}$ & 342 & 342 & 313 & 345 & 285 & 294 & 281 & 297 & 265 & 289 \\
$\mathbf{1 7}$ & $\mathbf{4 2 1}$ & 437 & 395 & 399 & 360 & 397 & 367 & 368 & 368 & 365 \\
$\mathbf{1 9}$ & 355 & 307 & 317 & 286 & 305 & 278 & 292 & 275 & 289 & 274 \\
$\mathbf{9}$ & 385 & 392 & 338 & 393 & 349 & 371 & 328 & 378 & 326 & 344 \\
$\mathbf{2 8}$ & $\mathbf{4 7 3}$ & 483 & 438 & 432 & 417 & 396 & 370 & 390 & 399 & 375 \\
Média & $\mathbf{3 7 0}$ & $\mathbf{3 5 9}$ & $\mathbf{3 3 9}$ & $\mathbf{3 5 1}$ & $\mathbf{3 2 3}$ & $\mathbf{3 2 8}$ & $\mathbf{3 1 0}$ & $\mathbf{3 1 9}$ & $\mathbf{3 0 4}$ & $\mathbf{3 1 0}$ \\
E.p.m. & $\mathbf{1 2}$ & $\mathbf{1 5}$ & $\mathbf{1 2}$ & $\mathbf{1 2}$ & $\mathbf{1 2}$ & $\mathbf{1 2}$ & $\mathbf{1 1}$ & $\mathbf{1 2}$ & $\mathbf{1 2}$ & $\mathbf{1 1}$
\end{tabular}

Efeito do estímulo precedente nas assincronias de 50,100, 150, 200 e $250 \mathrm{~ms}$ no Experimento 4, com linhas horizontais e verticais de baixa intensidade distribuídas no fundo da tela (tempo de reação na condição oposta - tempo de reação na condição mesma).

\begin{tabular}{c|ccccc} 
AIE & $\mathbf{5 0}$ & $\mathbf{1 0 0}$ & $\mathbf{1 5 0}$ & $\mathbf{2 0 0}$ & $\mathbf{2 5 0}$ \\
\hline $\mathbf{1}$ & -23 & 8 & 15 & 7 & -2 \\
$\mathbf{4}$ & -7 & 12 & 24 & 28 & -24 \\
$\mathbf{5}$ & 14 & 18 & 11 & 10 & 25 \\
$\mathbf{6}$ & 1 & 3 & -12 & -21 & -4 \\
$\mathbf{7}$ & 25 & 61 & 16 & 28 & 29 \\
$\mathbf{1 3}$ & 25 & -6 & -2 & 9 & -3 \\
$\mathbf{1 5}$ & 8 & -2 & -18 & -16 & 44 \\
$\mathbf{1 6}$ & 0 & 32 & 9 & 16 & 24 \\
$\mathbf{1 7}$ & 16 & 4 & 37 & 1 & -3 \\
$\mathbf{1 9}$ & -48 & -31 & -27 & -17 & -15 \\
$\mathbf{9}$ & 7 & 55 & 22 & 50 & 18 \\
$\mathbf{2 8}$ & 10 & -6 & -21 & 20 & -24 \\
Média & $\mathbf{2}$ & $\mathbf{1 2}$ & $\mathbf{5}$ & $\mathbf{1 0}$ & $\mathbf{5}$ \\
E.p.m. & $\mathbf{6}$ & $\mathbf{8}$ & $\mathbf{6}$ & $\mathbf{6}$ & $\mathbf{6}$
\end{tabular}




\section{ANEXO I - Tabelas de dados do Experimento 5}

Tempos de reação (em ms) nas assincronias de 100, 400 e 800 ms no Experimento 5A, com demarcações na tela. LVE: linha vertical, mão esquerda; LVD: linha vertical, mão direita; AD: anel, mão direita; AE: anel, mão esquerda.

\begin{tabular}{l|ccccccc} 
& AIE & \multicolumn{2}{c}{$\mathbf{1 0 0}$} & \multicolumn{2}{c}{$\mathbf{4 0 0}$} & \multicolumn{2}{c}{$\mathbf{8 0 0}$} \\
\hline & E1-E2 & $\mathbf{M}$ & $\mathbf{0}$ & $\mathbf{M}$ & $\mathbf{0}$ & $\mathbf{M}$ & $\mathbf{0}$ \\
LVE/AD & 1 & 534 & 546 & 497 & 527 & 514 & 517 \\
LVE/AD & 2 & 561 & 594 & 579 & 574 & 591 & 575 \\
LVE/AD & 3 & 517 & 511 & 477 & 509 & 479 & 498 \\
LVE/AD & 5 & 473 & 492 & 468 & 477 & 472 & 476 \\
LVE/AD & 6 & 419 & 428 & 435 & 424 & 422 & 406 \\
LVE/AD & 9 & 445 & 476 & 444 & 459 & 452 & 456 \\
LVD/AE & 10 & 493 & 518 & 476 & 509 & 495 & 476 \\
LVD/AE & 16 & 497 & 486 & 481 & 491 & 461 & 462 \\
LVD/AE & 17 & 436 & 442 & 420 & 429 & 426 & 420 \\
LVD/AE & 21 & 556 & 556 & 531 & 532 & 529 & 526 \\
LVD/AE & 23 & 462 & 458 & 453 & 486 & 501 & 465 \\
LVD/AE & 25 & 460 & 491 & 480 & 450 & 462 & 440 \\
& Média & $\mathbf{4 9 3}$ & $\mathbf{5 0 5}$ & $\mathbf{4 8 1}$ & $\mathbf{4 9 3}$ & $\mathbf{4 8 4}$ & $\mathbf{4 8 1}$ \\
& E.p.m. & $\mathbf{1 6}$ & $\mathbf{1 6}$ & $\mathbf{1 5}$ & $\mathbf{1 5}$ & $\mathbf{1 6}$ & $\mathbf{1 6}$
\end{tabular}

Efeito do estímulo precedente nas assincronias de 100, 400 e $800 \mathrm{~ms}$ no Experimento $5 \mathrm{~A}$, com demarcações na tela (tempo de reação na condição oposta - tempo de reação na condição mesma). LVE: linha vertical, mão esquerda; LVD: linha vertical, mão direita; AD: anel, mão direita; AE: anel, mão esquerda.

\begin{tabular}{l|r|ccc} 
& \multicolumn{1}{|l|}{ AIE } & $\mathbf{1 0 0}$ & $\mathbf{4 0 0}$ & $\mathbf{8 0 0}$ \\
\hline LVE/AD & E1-E2 & & & \\
LVE/AD & $\mathbf{1}$ & 12 & 30 & 3 \\
LVE/AD & $\mathbf{2}$ & 34 & -5 & -16 \\
LVE/AD & $\mathbf{3}$ & -5 & 32 & 18 \\
LVE/AD & $\mathbf{5}$ & 19 & 9 & 4 \\
LVE/AD & $\mathbf{6}$ & 9 & -11 & -17 \\
LVD/AE & $\mathbf{1 0}$ & 25 & 15 & 4 \\
LVD/AE & $\mathbf{1 6}$ & -11 & 33 & -19 \\
LVD/AE & $\mathbf{1 7}$ & 7 & 9 & 1 \\
LVD/AE & $\mathbf{2 1}$ & 0 & 2 & -6 \\
LVD/AE & $\mathbf{2 3}$ & -4 & 32 & -3 \\
LVD/AE & $\mathbf{2 5}$ & 31 & -30 & -22 \\
& Média & $\mathbf{1 2}$ & $\mathbf{1 0}$ & $\mathbf{- 7}$ \\
& E.p.m. & $\mathbf{4}$ & $\mathbf{6}$ & $\mathbf{4}$
\end{tabular}


Tempos de reação (em ms) nas assincronias de 100, 400 e 800 ms no Experimento 5B, sem demarcações na tela. LVE: linha vertical, mão esquerda; LVD: linha vertical, mão direita; AD: anel, mão direita; AE: anel, mão esquerda.

\begin{tabular}{l|ccccccc} 
& AIE & $\mathbf{1 0 0}$ & & $\mathbf{4 0 0}$ & $\mathbf{8 0 0}$ & \\
\hline & E1-E2 & $\mathbf{M}$ & $\mathbf{0}$ & $\mathbf{M}$ & $\mathbf{0}$ & $\mathbf{M}$ & $\mathbf{0}$ \\
LVE/AD & 2 & 442 & 449 & 434 & 434 & 395 & 411 \\
LVE/AD & 3 & 391 & 388 & 367 & 363 & 381 & 373 \\
LVE/AD & 4 & 479 & 488 & 505 & 501 & 480 & 475 \\
LVE/AD & 12 & 499 & 463 & 460 & 478 & 454 & 448 \\
LVE/AD & 14 & 482 & 498 & 482 & 476 & 475 & 484 \\
LVE/AD & 15 & 463 & 468 & 438 & 408 & 441 & 438 \\
LVD/AE & 17 & 627 & 643 & 588 & 625 & 573 & 612 \\
LVD/AE & 18 & 572 & 598 & 570 & 539 & 524 & 495 \\
LVD/AE & 19 & 583 & 590 & 555 & 547 & 597 & 610 \\
LVD/AE & 21 & 452 & 461 & 408 & 424 & 390 & 397 \\
LVD/AE & 22 & 508 & 494 & 505 & 511 & 487 & 469 \\
LVD/AE & 23 & 464 & 474 & 468 & 461 & 446 & 445 \\
& Média & $\mathbf{4 9 7}$ & $\mathbf{5 0 1}$ & $\mathbf{4 8 2}$ & $\mathbf{4 8 1}$ & $\mathbf{4 7 0}$ & $\mathbf{4 7 1}$ \\
& E.p.m. & $\mathbf{1 9}$ & $\mathbf{2 1}$ & $\mathbf{1 9}$ & $\mathbf{2 0}$ & $\mathbf{2 0}$ & $\mathbf{2 1}$
\end{tabular}

Efeito do estímulo precedente nas assincronias de 100, 400 e $800 \mathrm{~ms}$ no Experimento 5B, sem demarcações na tela (tempo de reação na condição oposta - tempo de reação na condição mesma). LVE: linha vertical, mão esquerda; LVD: linha vertical, mão direita; AD: anel, mão direita; AE: anel, mão esquerda.

\begin{tabular}{l|c|ccc} 
& \multicolumn{1}{|l|}{ AIE } & $\mathbf{1 0 0}$ & $\mathbf{4 0 0}$ & $\mathbf{8 0 0}$ \\
\hline LVE/AD & E1-E2 & & & \\
LVE/AD & $\mathbf{2}$ & 7 & 0 & 16 \\
LVE/AD & $\mathbf{3}$ & -2 & -4 & -8 \\
LVE/AD & $\mathbf{4}$ & 9 & -5 & -5 \\
LVE/AD & $\mathbf{1 2}$ & -36 & 18 & -7 \\
LVE/AD & $\mathbf{1 4}$ & 16 & -6 & 8 \\
LVD/AE & $\mathbf{1 5}$ & 5 & -31 & -3 \\
LVD/AE & $\mathbf{1 7}$ & 16 & 37 & 39 \\
LVD/AE & $\mathbf{1 8}$ & 26 & -31 & -29 \\
LVD/AE & $\mathbf{1 9}$ & 7 & -8 & 13 \\
LVD/AE & $\mathbf{2 1}$ & 9 & 16 & 8 \\
LVD/AE & $\mathbf{2 3}$ & -15 & 6 & -18 \\
& Média & $\mathbf{4}$ & -7 & -1 \\
& E.p.m. & $\mathbf{5}$ & $\mathbf{- 1}$ & $\mathbf{1}$ \\
& & & 5
\end{tabular}

